\title{
CABAÑAS DE ÉPOCA VISIGODA: EVIDENCIAS ARQUEOLÓGICAS DEL SUR DE MADRID. TIPOLOGÍA, ELEMENTOS DE DATACIÓN Y DISCUSIÓN
}

\author{
POR \\ ALFONSO VIGIL-ESCALERA GUIRADO \\ Arqueólogo de AREA, Sociedad Cooperativa. Madrid
}

PALABRAS CLAVE: Poblados visigodos. Fondos de cabaña. Cerámica visigoda. Necrópolis. Yacimiento de La Indiana-Cacera del Valle (Pinto, Madrid). Yacimiento de Gózquez de Arriba (San Martín de la Vega, Madrid). Siglos V-XI.

KEY WORDS: Visigothic villages. Sunken huts. Visigothic pottery. Necropolis. Site of La Indiana-Cacera del Valle (Pinto, Madrid). Site of Gózquez de Arriba (San Martín de la Vega, Madrid). 5-11 th centuries.

\section{RESUMEN}

El convencimiento de que buena parte de los poblados rurales de época visigoda en llano se caracterizan por la presencia de cabañas semiexcavadas nos mueve a presentar por vez primera un intento de sistematización tipológica de estas estructuras arqueológicas poco conocidas en la península Ibérica. Unas responden a características que forman parte de la tradición campesina autóctona desde, al menos, la Edad del Bronce; otro conjunto podría ser específico de la época de las invasiones. Tras unos apuntes de cronología se repasan algunos temas de discusión sobre estos elementos de la arquitectura doméstica en otros ámbitos europeos.

\section{SUMMARY}

The conviction that a good number of the Visigothic rural sites provide sunken huts has led to the first attempt to systematize the typology of these archaeological structures, which are little known in the Iberian peninsula. Some of them show features that form part of the rural native tradition dating back at least to the Bronze Age; others may be specific to the period of invasions. A few chronological notes are followed by a brief discussion of these domestic architectural features in other European contexts.

1. INTRODUCCIÓN. PROBLEMAS TERMINOLÓGICOS Y DE INTERPRETACIÓN DE LA EVIDENCIA (O POR QUÉ LLAMAMOS CABAÑAS A LOS FONDOS DE CABAÑA)

Antes de abordar el tema del presente trabajo aludiremos al conflicto terminológico planteado por la elección del título del mismo. Hemos renunciado al uso de la expresión «fondo de cabaña» (que sin embargo se atiene fielmente a las características de las estructuras arqueológicas que se describirán más adelante) debido a la confusión que ha establecido sobre ese concepto una arraigada costumbre en la literatura arqueológica española. Nuestro criterio, mientras no se limite el uso de ese término a su correspondiente semántico entre el colectivo de arqueólogos, será el de denominar cabaña al hoyo correspondiente al suelo excavado de una cabaña o al espacio subterráneo (de almacenamiento, aireación o «cama») de cualquier tipo de estructura residencial o auxiliar identificable como tal, de igual modo que llamamos silo a la parte del hoyo de almacenamiento subterráneo que se documenta habitualmente en las excavaciones, aunque no siempre aparezca la estructura completa ${ }^{1}$.

Las estructuras arqueológicas que se describirán a continuación son parte de cabañas, y como tales, presentan una serie de rasgos que permiten su diferenciación con claridad de otros hoyos excavados en el terreno como pueden ser silos, pozos, hornos u otras estructuras arqueológicas de más compleja interpretación.

En términos funcionales, buena parte de ellas podría interpretarse como estructuras residenciales, aunque esta asignación no implique un carácter de exclusividad. Algunas, debido a su deficiente estado de conservación o a unas posibilidades de registro insuficientes, ofrecen un margen de indeterminación que, sin embargo, no debiera impedir su adscripción funcional a elementos auxiliares subsidiarios de los residenciales, lo que incluiría actividades relacionadas con el almacenamiento o procesado de productos agrícolas, entre otras. La utilización del fondo de la mayoría de estas estructuras y del espacio interior resultante queda demostrado por la existencia de diferentes modos de acceso ${ }^{2}$ (rampas, gradas excavadas en la pared, etc.), por la utilización desde el inte-

1 Esta confusión terminológica ya fue apreciada hace más de veinte años: «en la mayor parte de los casos, estos términos (silo, basurero, cenicero, fondo de cabaña) deben ser excluyentes» (Martínez Navarrete, 1979: 102). Sin embargo, poco se ha arreglado desde entonces.

2 Algunos paralelos etnográficos (Milosevic, 1998: fig. 171) demuestran la variedad tipológica de esos sistemas de acceso, a veces constituidos por elementos de madera (escaleras, troncos con muescas...) de difícil contrastación arqueológica. 


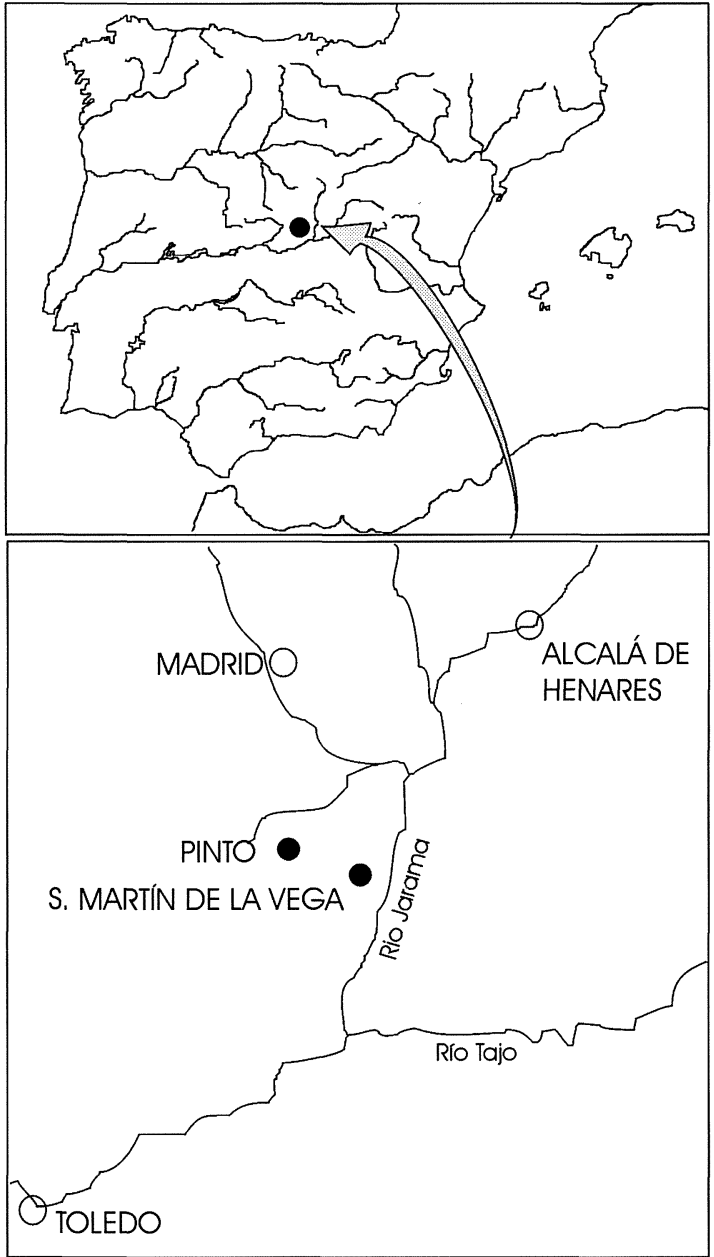

Fig. 1.-Situación de los yacimientos citados en el texto.

rior de estructuras de cocina-calefacción (hornos) y por el descubrimiento, en algunos casos, de estratos de suelo compuestos por una mezcla homogénea de yesos y arcilla, a veces con improntas vegetales.

Lamentablemente, no se han podido aducir paralelos etnográficos en la península Ibérica que permitan esclarecer las dudas que arrojan determinados elementos internos documentados en el curso de la excavación (ciertos nichos u oquedades en las paredes del hoyo, determinadas huellas de poste de planta rectangular, etc.). A este respecto, resulta confortable comprobar el grado de relación existente entre la evidencia arqueológica y la etnográfica en la arquitectura popular rural de otras zonas de la geografía europea, tal y como G. Milosevic ha establecido para estructuras residenciales de yacimientos altomedievales de la antigua Serbia (Milosevic, 1998) ${ }^{3}$.

${ }^{3}$ El trabajo citado constituye una excelente monografía arqueológica sobre arquitectura popular. Resulta sorprenden-

\section{YACIMIENTOS DE REFERENCIA}

Los yacimientos en los que se han documentado arqueológicamente las cabañas entre los años 1997 y 1999 quedan enclavados en la mitad meridional de la Comunidad de Madrid, sobre terrenos aluvio-coluvionales o detríticos, con escasez de piedra como material constructivo y que permiten la construcción de estructuras subterráneas sin excesiva dificultad (fig. 1). En ambos casos se aprecia una ubicación inmediata a cursos de agua menores o zonas encharcadas buena parte del año.

El primero de ellos recibe el nombre de La Indiana-Cacera del Valle, y se sitúa en el término municipal de Pinto, bajo el actual barrio «Parque Europa», al Norte del pueblo. La excavación arqueológica de urgencia allí desarrollada, auspiciada por el Ayuntamiento de Pinto y la Dirección General de Patrimonio de la Comunidad de Madrid, permitió documentar evidencias de sucesivas ocupaciones o frecuentación paleolítica, prehistórica y de época altoimperial romana, además de una parte significativa de un poblado o suburbio tardorromano y altomedieval. Las parcelas en las que se documentaron vestigios de estos últimos períodos (superpuestos a los de anteriores ocupaciones, sin aparente continuidad) suman una superficie excavada de alrededor de una hectárea $\left(2.900 \mathrm{~m}^{2}\right.$ en la parcela denominada Cacera del Valle y $6.600 \mathrm{~m}^{2}$ en las dos parcelas contiguas de La Indiana; fig. 2). La distribución en extensión de las evidencias arqueológicas descubiertas permite suponer que el poblado debe ser bastante más amplio, con núcleos dispersos a escasa distancia unos de otros ${ }^{4}$.

Las principales estructuras arqueológicas documentadas responden a cuatro tipos básicos: cabañas, silos, enterramientos y pozos. La cronología del conjunto abarca desde la segunda mitad del siglo $\mathrm{v}$ al X-XI d.n.e.

Las actuaciones arqueológicas en terrenos de la finca Gózquez de Arriba (San Martín de la Vega) se desarrollaron a lo largo de sucesivas campañas durante los años 1997 (labores de peritación arqueológica bajo la dirección de D. Antonio Fernández Ugalde), 1998 y 1999 (sucesivas campañas de verificación de la potencialidad arqueológica, excava-

te comprobar la estrecha semejanza existente entre la evidencia arqueológica de zonas tan alejadas. Agradecemos a Pedro Díaz del Río y a $\mathrm{M}^{\mathrm{a}}$ Isabel Martínez Navarrete la información proporcionada sobre este trabajo de investigación.

4 Incluso con dos zonas cementeriales diferentes. Antes de nuestra intervención, otros equipos habían desarrollado en las parcelas del PAU Norte de Pinto diversas campañas de peritación arqueológica, excavación de los viales y excavación parcial de las necrópolis y de una parte del asentamiento del Bronce Final. 


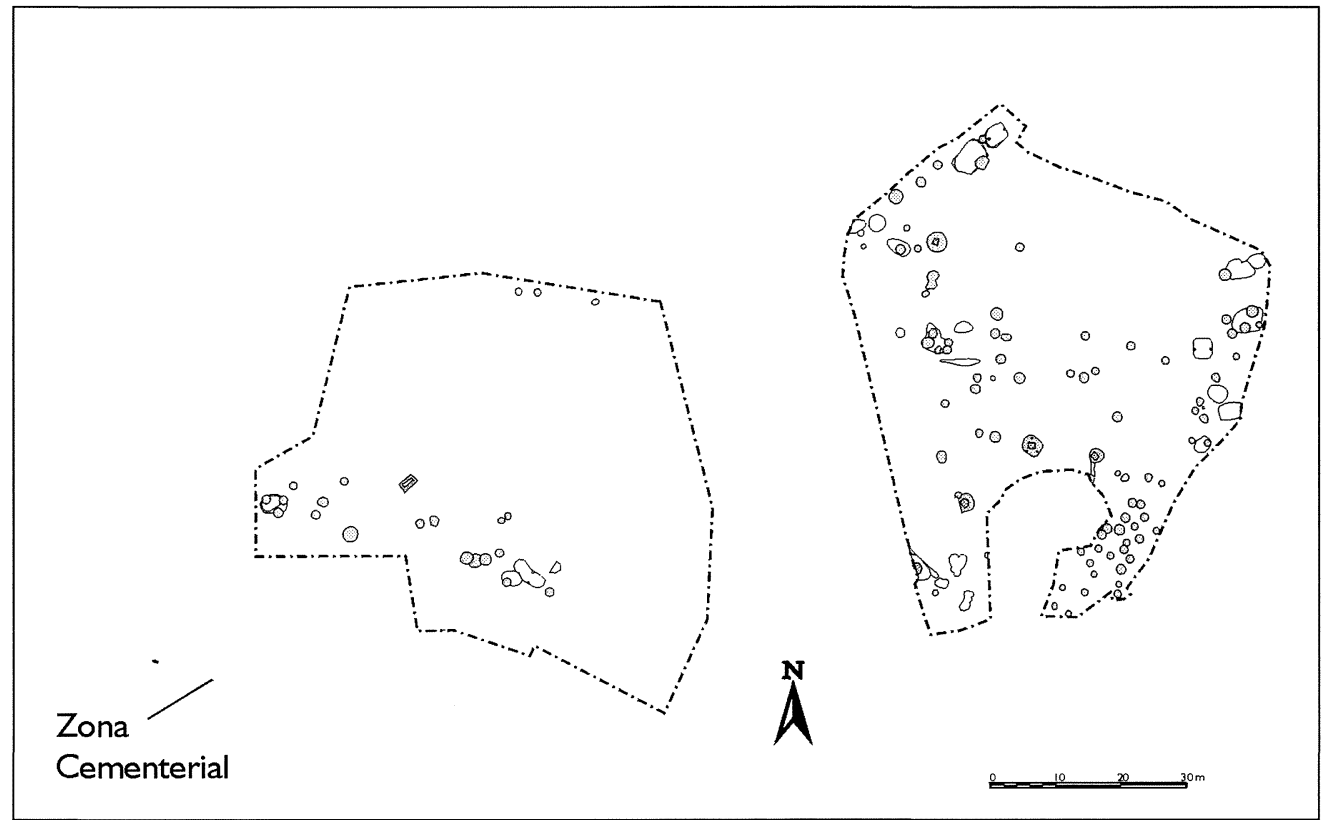

Fig. 2.-Planta general del área excavada del yacimiento de «La Indiana» (Pinto, Madrid). Fase tardorromanaaltomedieval. Escala 1/1500

ción extensiva y supervisión de las obras de replanteo del futuro Parque Temático «Ciudad del Ocio» de la Comunidad de Madrid, desde julio de 1998 a septiembre de 1999). Los trabajos arqueológicos fueron costeados por la empresa ARPEGIO, promotora del proyecto de urbanización, a excepción de la campaña estival de 1998, sufragada con cargo a los presupuestos de la Dirección General de Patrimonio de la Comunidad de Madrid.

La superficie excavada del asentamiento ha sido de unos $23.900 \mathrm{~m}^{2}$ a los que habría que sumar los 4.400 de la necrópolis (fig. 3). De acuerdo a los planteamientos previos de la intervención arqueológica (que contó con la supervisión y apoyo de los servicios técnicos de arqueología de la Dirección General de Patrimonio de la Comunidad de Madrid), se excavó íntegramente la zona afectada por futuras zanjas y desmontes y se llevó a cabo un muestreo amplio y una documentación exhaustiva en planta de las zonas del yacimiento que resultarían sepultadas por terraplenes. A resultas de las diferentes actuaciones se pudo verificar que la extensión del poblado (zona de necrópolis incluida) alcanzaba una superficie aproximada de algo más de diez hectáreas siguiendo un modelo de implantación sólo aparentemente caótico, a lo largo de una serie de pequeños cerros y laderas suaves que descienden hasta la orilla meridional del arroyo de Gózquez, subsidiario del de la Vega de Madrid, en la margen oriental del Jarama.
La tipología de los elementos excavados del poblado es similar a la registrada en los yacimientos de Pinto (cabañas, silos, pozos, enterramientos) con algunos añadidos complementarios: se documentaron edificaciones de planta rectangular con cimientos de piedra y alzados en tapial de yeso con cubiertas de teja curva y estructuras de carácter lineal que responden, al parecer, a delimitaciones parcelarias correspondientes a diversas épocas, algunas de ellas pertenecientes a los momentos de implantación de la comunidad sobre esos terrenos a principios del siglo vi d.n.e. El abandono del asentamiento tuvo lugar, según las primeras estimaciones, a finales del siglo viII d.n.e. ${ }^{5}$.

\section{DOS APUNTES METODOLÓGICOS Y OTRO DE TAFONOMÍA}

Antes de entrar en la descripción y somero análisis de las cabañas documentadas en ambos yacimientos se matizará un par de aspectos metodológi-

${ }^{5}$ Una intervención arqueológica de urgencia en mayo de 2000 ha permitido documentar un nuevo yacimiento de las mismas características, con cabañas y necrópolis asociada en el término de Mejorada del Campo, en la margen occidental del Jarama. Las características de la excavación (un corredor de $50 \mathrm{~m}$ de longitud por $6 \mathrm{~m}$ de anchura) y lo reciente de la misma sólo nos permiten, en este espacio, reafirmarnos en lo frecuentes que resultan este tipo de yacimientos en el paisaje del sur de Madrid. 


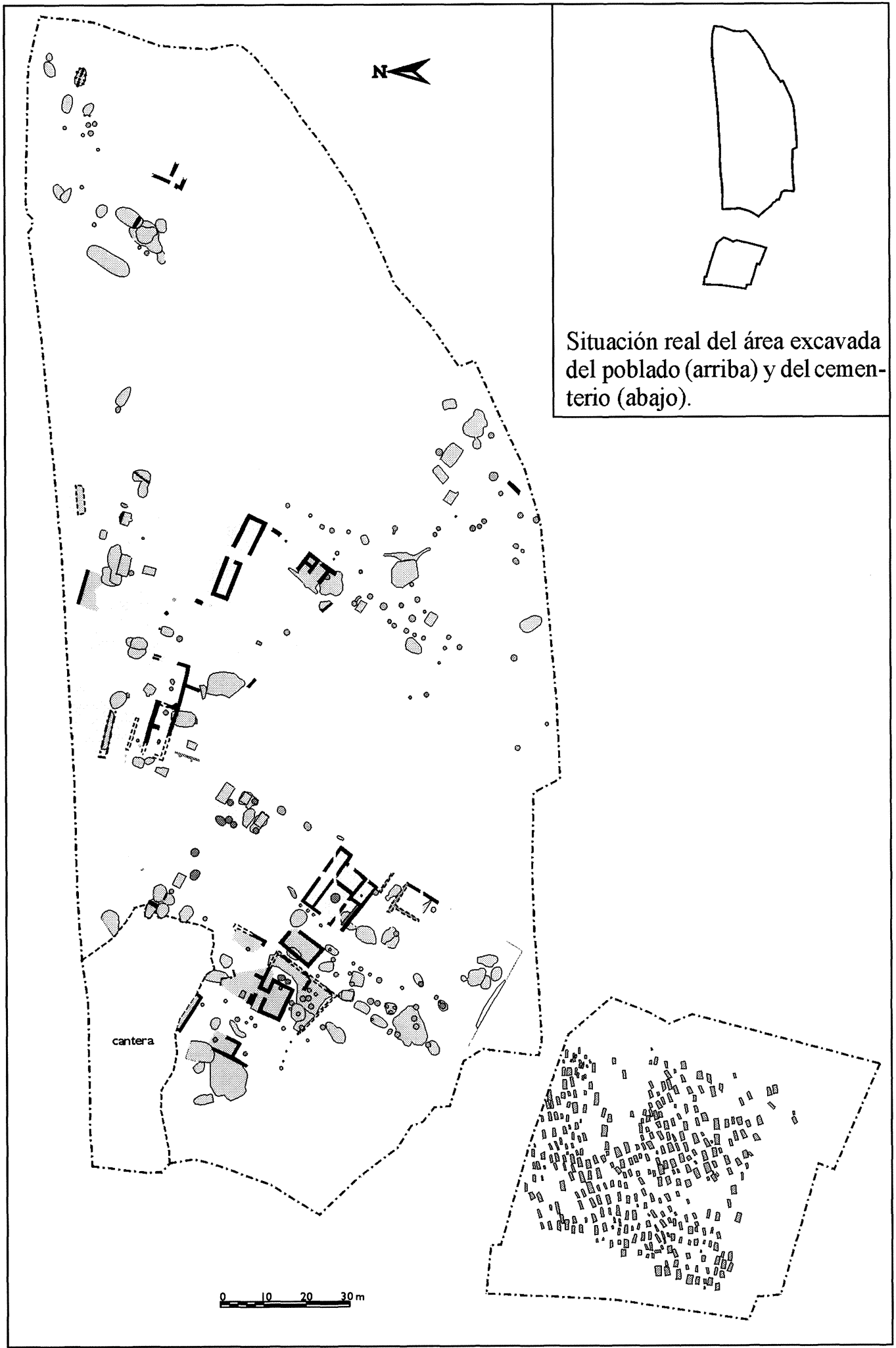

Fig. 3.-Planta general del área excavada del yacimiento de Gózquez de Arriba (S. Martín de la Vega, Madrid). Escala 1/1500. 
cos de los procesos de excavación y registro que tienen la mayor importancia.

Los resultados de las excavaciones arqueológicas desarrolladas son fruto de un sistema de excavación y registro estrictamente estratigráfico y de un planteamiento metodológico riguroso. Sin un proceso de desbroce superficial preciso y extensivo (auxiliado con la maquinaria pesada acondicionada al efecto ${ }^{6}$ ) y una extracción y limpieza estrictamente manual de toda la parte restante del terreno húmico superficial no será posible documentar los eventuales restos de estratificación horizontal preservados en el yacimiento. De he-

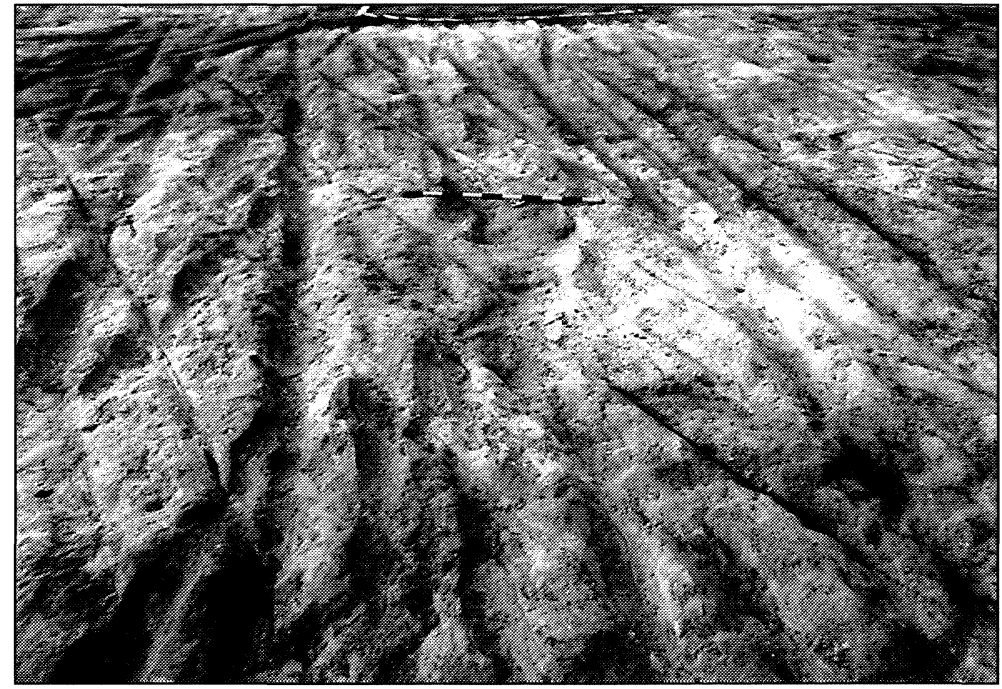

Fig. 4.-Huellas de arado modernas, responsables principales del arrasamiento de amplios sectores del yacimiento de Gózquez. tos básicos de topografía o una estación total mejoran la calidad del trabajo ayudando a situar y acotar todas las evidencias incluso antes de iniciarse la remoción de la estratigrafía. Las plantas generales del yacimiento van superponiéndose y enriqueciéndose de detalles a medida que avanza la excavación. Éstas ayudan a visualizar de una manera global el sitio arqueológico (se hacen patentes las relaciones entre estructuras) y animan a los diferentes equipos de excavadores que comprueban cómo el yacimiento se va haciendo comprensible.

El segundo aspecto sobre el que debiera llamarse la atención concierne a la proporción de la superficie excavada y la dispersión espacial de estructuras arqueológicas en este tipo de poblados. Sin la apertura y limpieza de grandes áreas (con un mínimo cifrable en unos $5.000 \mathrm{~m}^{2}$ ), la imagen de los yacimientos presentará importantes distorsiones (Rahtz, 1986: 53-54). Los espacios vacíos cobran sentido solamente cuando se logra documentar en planta una superficie lo suficientemente grande, siendo inimaginable la posibilidad de una adecuada comprensión de este tipo de yacimientos sin unas estrategias de excavación extensivas.

Una premisa general acerca de todas las estructuras arqueológicas que se presentan a continuación arranca del hecho de que estas cabañas están constituidas por una parte «aérea», de la que no podemos aducir más que paralelos y reconstrucciones más o menos fiables, y una parte «subterránea», que es la más fácilmente identificable a través del registro arqueológico con el reconocimiento de la interfaz negativa correspondiente a la parte excavada de la misma. 


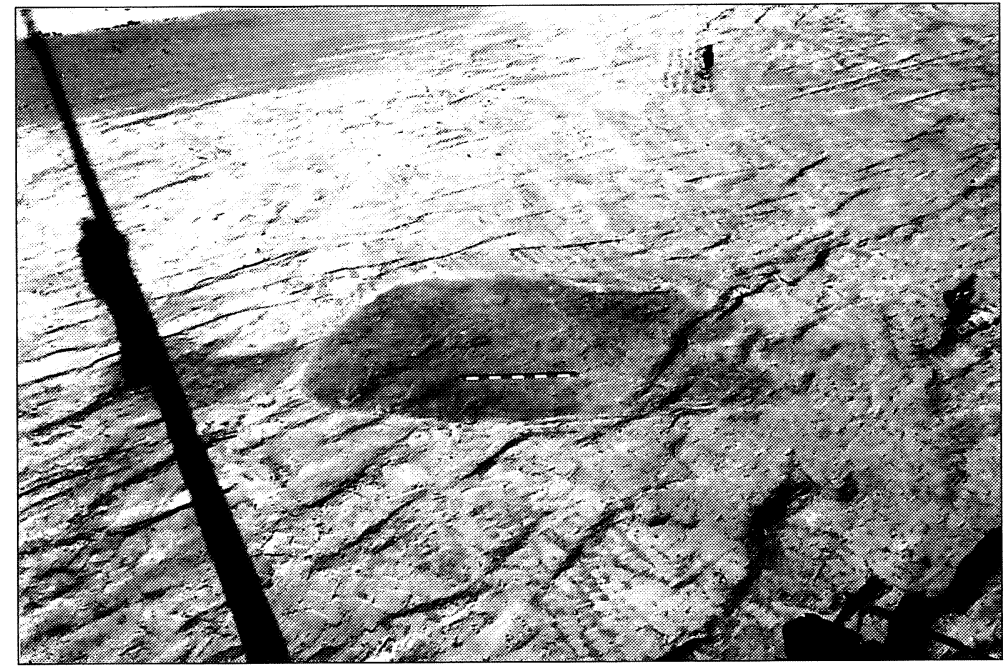

Fig. 5.-Cabaña con estructura menor asociada, antes de su excavación.

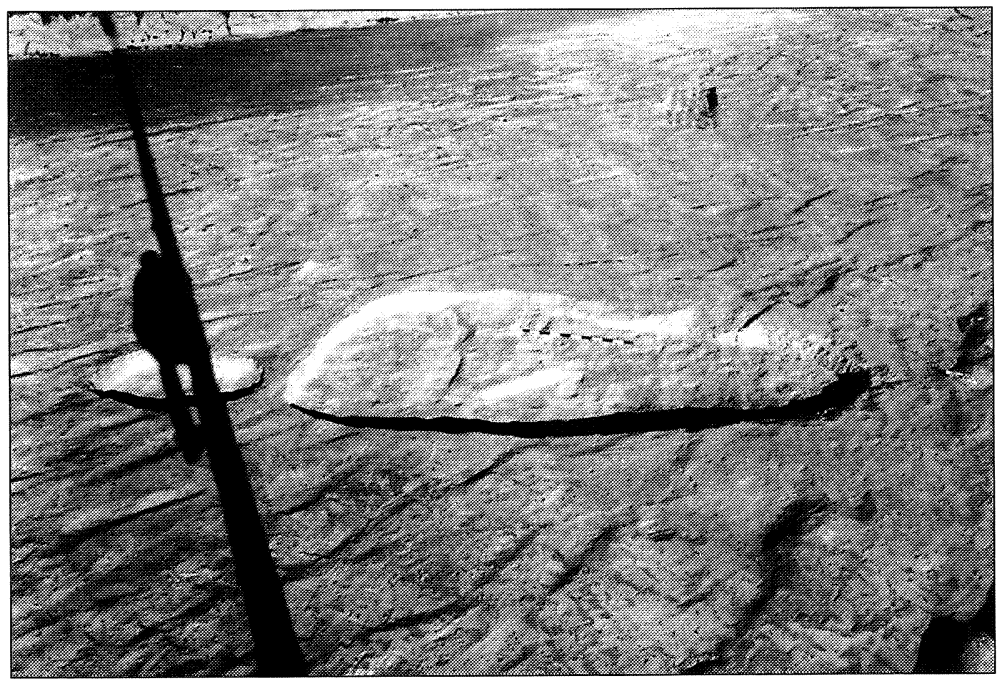

Fig. 6.-Las estructuras anteriores (5250 y 5260) una vez excavadas. En esta zona, el arrasamiento superficial comprobado supera los $0,8 \mathrm{~m}$.

cuencia de la gravedad favorecida por causas antrópicas) han supuesto una pérdida sustancial del registro arqueológico original. De hecho, algunas estructuras han llegado a nuestros días habiendo perdido hasta $0,8 \mathrm{~m}$ de potencia, lo que condiciona enormemente la lectura de muchas secciones ${ }^{7}$ (figs. 5 y 6). El análisis de ciertos procesos deposicionales y postdeposicionales no sólo tiene una importancia crucial para la interpretación de los ritmos y causas de colmatación de algunos hoyos, sino que implica necesariamente una precaución especial en la interpretación de las secciones de muchas estructuras subterráneas. En el yacimiento de Gózquez, el descubrimiento de algunos silos completos (incluso con el sistema de embocadura y la tapadera de piedra in situ) ha posibilitado una reconstrucción y una interpretación muy ajustada de toda la parte superior perdida por causas postdeposicionales de silos, bodegas y cabañas y ser conscientes de la parcialidad del registro arqueológico en lo tocante a la eventual estratificación horizontal asociada a determinadas estructuras del yacimiento. Su conservación depende en muchos casos de factores sumamente aleatorios (la superposición de casas con cimientos de piedra a estructuras preexistentes, por ejemplo, ha

A este respecto y hecha la salvedad anterior, conviene matizar por adelantado qué parte del registro arqueológico ha llegado a nosotros y en qué condiciones (la tafonomía de la parte subterránea de las cabañas). De hecho, la comprobación llevada a cabo con las secciones de los silos para determinar la cota de arrasamiento de determinadas partes del yacimiento excavado en Gózquez ha permitido precisar cuáles de las estructuras han sido documentadas casi en su integridad y hasta qué punto fenómenos más o menos generalizados de arrasamiento (bien por el trabajo secular de los arados, por escorrentía superficial en algunas laderas $y$, en suma, a conse- impedido a los arados consumar el arrasamiento de diversas zonas).

\section{TIPOLOGÍA}

Este intento de establecer una sistematización tipológica de las cabañas de época visigoda a partir de las exhumadas recientemente en el sur de Madrid parte con algunas ventajas y ciertos inconvenientes.

7 Este factor nos ha movido a adoptar una cautela especial respecto a todo lo referente a la profundidad de las cabañas que se presentan a continuación. 
Entre las primeras destaca que se trata de un asunto no tratado con anterioridad en nuestro ámbito peninsular, pero que ya se ha probado con mayor o menor éxito en otras regiones europeas. Los inconvenientes se derivan del pequeño tamaño de la muestra (alrededor de unos 70 ejemplos) y de lo que parece ser una cierta especificidad del repertorio disponible respecto a lo observado fuera de la península Ibérica (lo abundantemente representadas que están las cabañas de planta ovalada). Seguramente el trabajo se vería muy mejorado si se pudiese abordar con una perspectiva diacrónica (con el análisis de la tradición constructiva de cabañas desde época prehistórica), pero esto es algo que queda fuera de nuestra capacidad y de los más inmediatos objetivos propuestos.

En la literatura arqueológica europea se conoce a este tipo de cabañas como «Grubenhäuser» (casas excavadas), «sunken feature building» (edificio de perfil rehundido), «sunken hut» (cabaña hundida) o «fond de cabane» (fondo de cabaña). Una escueta definición de estas estructuras arqueológicas a partir del repertorio francés de hace algunos años fué la siguiente: «se trata de instalaciones parcialmente excavadas en el suelo entre $25 \mathrm{~cm}$ y un metro, con una superficie comprendida entre 5 y $10 \mathrm{~m}^{2}$, raramente más. En la inmensa mayoría de casos, son estructuras rectangulares, aunque se conocen algunos casos de fondos de cabaña ovalados» (ChapelotFossier, 1980: 117. Fig. 7). Como veremos, en la muestra hispana las cabañas de planta ovalada parecen ser mayoritarias respecto a las cuadrangulares, y no son infrecuentes las estructuras excavadas con más de un metro de profundidad.

De manera preliminar, todas las cabañas documentadas pueden encuadrarse en dos tipos fundamentales: unas responden a criterios constructivos que restringen la forma de su planta a un formato cuadrangular (tipo B), ya sea con esquinas en ángulos vivos o redondeados; el resto son de planta más o menos ovalada y presentan una gran variedad de formatos y dimensiones (tipo A). Es posible que la parte aérea de unas y otras reflejara a su vez diferencias significativas (cubiertas cónicas frente a techumbres a dos vertientes, por ejemplo). Por lo que respecta a la profundidad de la parte subterránea, se han documentado estructuras de entre 0,15 y $3,2 \mathrm{~m}$ de profundidad (téngase en cuenta la puntualización tafonómica hecha anteriormente), aunque lo habitual oscila entre los 0,5 y 1,2 m. Las cabañas que superan esta última profundidad pertenecen siempre a modelos de planta curvilínea ${ }^{8}$.

${ }^{8}$ La «subterraneidad» de las cabañas altomedievales, atestiguada tanto en la Europa de las estepas como en la at-

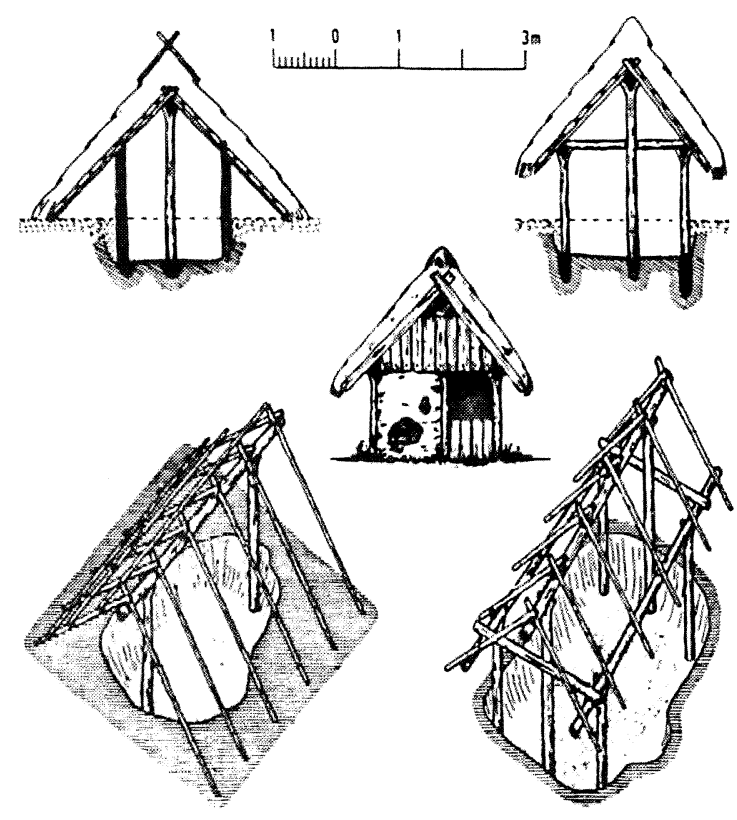

Fig. 7.-Modelos de cabaña de Gladbach (Alemania), según Chapelot-Fossier, 1980: fig. 33.

Por lo que se refiere al discurso diacrónico, no parece probable establecer una eventual evolución desde un tipo al otro (hecho observado también en otras partes de Europa ${ }^{9}$ ). Sin embargo, debe tenerse muy en cuenta que las cabañas de planta ovalada responden a unos criterios morfológicos idénticos a los documentados en estructuras de época prehistórica ${ }^{10} \mathrm{y}$ que, por otra parte, parece posible establecer unos límites cronológicos bastante ajustados para las cabañas rectangulares, sobre las que recaería la sospecha de que puedan ser la manifestación de tradiciones constructivas importadas en la época de las invasiones. Además, el repertorio del que se puede disponer en la actualidad señalaría la prácti-

lántica en este período no debe obedecer solamente a factores climáticos (autorregulación térmica) sino también a estrategias de ahorro de esfuerzo (el material extraído debe ser parte integrante de la parte construida), a motivos estructurales (la parte «aérea» ofrece mayor resistencia si se reduce su altura) y, quizás, a razones estratégicas de «ocultamiento» (integración mimética en el paisaje). Tácticas campesinas de mimetización con el entorno no deben haber sido infrecuentes en momentos de «resistencia al Estado» por parte de comunidades aldeanas herederas de un modo patrimonial de explotación (Vicent, 1998: 832-ss.).

${ }_{9}$ Milosevic, 1998: 238; Chapelot-Fossier, 1980: 131-133.

${ }_{10}$ Se han documentado cabañas con una forma en planta, dimensiones y características exactamente iguales a las de nuestro tipo A 1 en el cercano yacimiento prehistórico (Bronce Pleno) de la era de Gózquez (noticias amablemente proporcionadas por nuestros colegas S. Consuegra y P. Díaz del Río). 


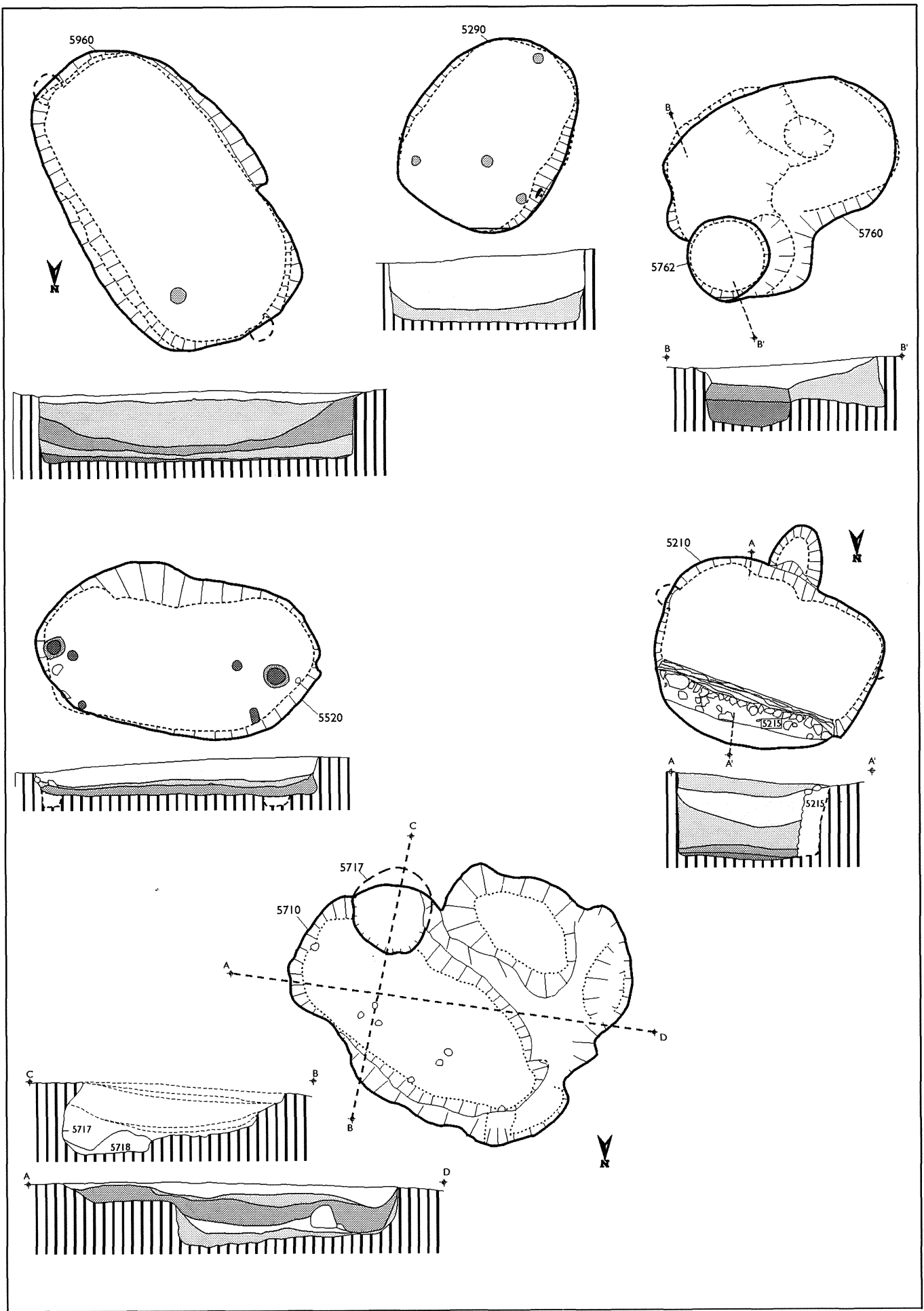

Fig. 8. - Plantas y secciones acumulativas de cabañas del tipo A1. Escala 1/100. 
ca desaparición de las cabañas de este útimo tipo a lo largo del siglo vil d.n.e. ${ }^{11}$.

\section{Cabañas de planta ovalada. Tipo A}

Es el tipo de cabaña más y mejor representado en los yacimientos de referencia (unos 50 ejemplos, más del $73 \%$ del total), contando con un variado repertorio formal y estructural. En algunos casos, la cabaña se presenta exenta, si bien es muy habitual su asociación a contenedores ${ }^{12}$ (situados en el perímetro del hoyo o en su interior) y a hornos (normalmente adosados por el exterior).

Se ha procedido a distinguir dos subtipos en función de las dimensiones de estas estructuras: la gran mayoría queda englobada dentro del primero (A1), mientras que en el segundo (A2) sólo se documentan algunos ejemplos singulares, con más de cinco metros de longitud y una superficie útil interior considerablemente mayor.

\section{Tipo Al (fig. 8)}

Cabaña ovalada simple, con o sin horno, silo o contenedor. El número de ejemplos de este tipo es el más elevado de cuantos componen la muestra (repartidos entre los dos yacimientos ${ }^{13}$ ). Sus dimensiones varían en torno a una media de $3,70 \mathrm{~m}$ de longitud (entre 2,65 y $4,85 \mathrm{~m}$ ) por $2,40 \mathrm{~m}$ de anchura (entre 1,65 y $3,5 \mathrm{~m}$ ), lo que da una superficie media útil de unos $7 \mathrm{~m}^{2}$. Algunas presentan huellas de postes en el suelo, en número y disposición variable; otras cuentan con pequeños nichos laterales excavados en las paredes del hoyo, a media altura o al nivel del suelo. En tres casos se han documentado muros construidos en el interior del hoyo. La cabaña G.5210 presenta una de las paredes forrada de mampostería (la opuesta al acceso, señalado por una rampa escalonada); en los otros ejemplos, el muro

1 Si se aceptara este tipo de cabañas como un indicador válido para identificar poblaciones de origen germánico o eslavo (cuestión a la que nos referiremos en el apartado 6.2), su desaparición podría probar la rápida aculturación de sus constructores al cabo de pocas generaciones.

12 Hoyo-contenedor es la denominación que se ha usado para definir a una serie de estructuras similares a los silos (parcialmente excavadas en el terreno) aunque de menor tamaño y embocadura más ancha. Posiblemente estén relacionados con el almacenamiento en el interior de las cabañas de productos alimentarios dentro de contenedores construidos con fibras vegetales trenzadas.

13 Al número de unidad estratigráfica correspondiente al hoyo de cada una de las cabañas le precederán las letras $\mathrm{C}$, L o $\mathrm{G}$ de acuerdo a su origen: Cacera del Valle, La Indiana o Gózquez. (con zócalo de piedra y probable alzado en adobe) cierra un lateral o deja en reserva un extremo de la cabaña como si se pretendiera aislar su interior de otras estructuras contemporáneas anejas. La finalidad de estos retranqueos internos, sin embargo, se resiste a una explicación unitaria. Su consecuencia inmediata es una restricción del espacio interior útil, aunque la inversión de trabajo realizada parece excesiva a ese único propósito.

Una interpretación funcional de las cabañas con silos u hoyos-contenedor asociados sería la relacionada con el almacenamiento a corto o medio plazo de productos alimenticios (durante la cosecha o inmediatamente después de ella) o con el tratamiento, selección o transformación de esos productos sin que puedan descartarse, sin embargo, otros fines secundarios.

CUADRO ESQUEMÁTICO DEL TIPO A1

\begin{tabular}{|c|c|c|c|}
\hline Identif. & Fase & Dimensiones & Observaciones \\
\hline C. 9100 & ss. VI-VIII & $3,55 \times 2,30 \mathrm{~m} \cdot 6,40 \mathrm{~m}^{2}$ & $\begin{array}{l}\text { Poste central calzado y } \\
\text { perimetrales }\end{array}$ \\
\hline L.2340 & ss. VI-VII & $3,7 \times 2,15 \mathrm{~m} \cdot 6,2 \mathrm{~m}^{2}$ & Silo centrado \\
\hline L.4001 & ss. VI-VIII & $4,75 \times 3,5 \mathrm{~m} \cdot 14,5 \mathrm{~m}^{2}$ & $\begin{array}{l}\text { Contenedores y silos en } \\
\text { perímetro }\end{array}$ \\
\hline L. 1400 & ss. VI-VII & $3,6 \times 2,6 \mathrm{~m} .8,15 \mathrm{~m}^{2}$ & \\
\hline L.4050 & ss. VI-VII & $3,1 \times 2,6 \mathrm{~m} \cdot 6,4 \mathrm{~m}^{2}$ & \\
\hline L.5300 & ss. VI-VII & $3,45 \times 2,4 \mathrm{~m} \cdot 7,00 \mathrm{~m}^{2}$ & \\
\hline L.6508 & ss. VI-VII & $3,2 \times 2,2 \mathrm{~m} \cdot 5,5 \mathrm{~m}^{2}$ & $\begin{array}{l}\text { Contenedor asociado, } \\
\text { muro interno. }\end{array}$ \\
\hline G.5960 & Ia & $4,85 \times 2,7 \mathrm{~m}$ & $\begin{array}{l}\text { Nichos en extremos } \\
\text { opuestos }\end{array}$ \\
\hline G.6450 & II & $2,65 \times 1,65 \mathrm{~m}$ & Dos postes axiales \\
\hline G. 5620 & Ia & $3,30 \times 2,05 \mathrm{~m}$ & \\
\hline G. 5210 & III & $3,35 \times 1,85 \mathrm{~m}$ & $\begin{array}{l}\text { Fondo forrado de mam- } \\
\text { postería }\end{array}$ \\
\hline G. 5520 & $\mathrm{Ib}$ & $4,15 \times 2,35 \mathrm{~m}$ & Dos postes axiales \\
\hline G. 5650 & III & $4,00 \times 2,50 \mathrm{~m}$ & \\
\hline G.5710 & III & $4,15 \times 2,10 \mathrm{~m}$ & Contenedor \\
\hline G.6830 & $\mathrm{Ib}$ & $4,40 \times 2,65 \mathrm{~m}$ & Horno \\
\hline G.5290 & III & $2,90 \times 2,30 \mathrm{~m}$ & Cuatro postes \\
\hline G.5760 & II & $3,50 \times 2,20 \mathrm{~m}$ & Contenedor \\
\hline
\end{tabular}

Tipo A2 (figs. 9 y 10)

Cabaña de planta ovalada alargada de grandes dimensiones. Cinco estructuras responden a este criterio, cuatro de ellas documentadas en el poblado de Gózquez (G.5150, G.5084, G.5640 y G.5453) y una en La Indiana (L.6307). Sus dimensiones, características internas y estado de conservación es bastante variable: sus longitudes oscilan entre los 5,2 y los $10,9 \mathrm{~m}$, con una anchura restringida a $2,2 / 3,85 \mathrm{~m}$. Una característica llamativa radica en el hecho de localizarse muy separadas (a excepción de G.5150 y G.5640), como si se tratara de elementos singulares ( ¿de uso comunal o con función centralizadora?), relacionadas cada una de ellas con alguna de 


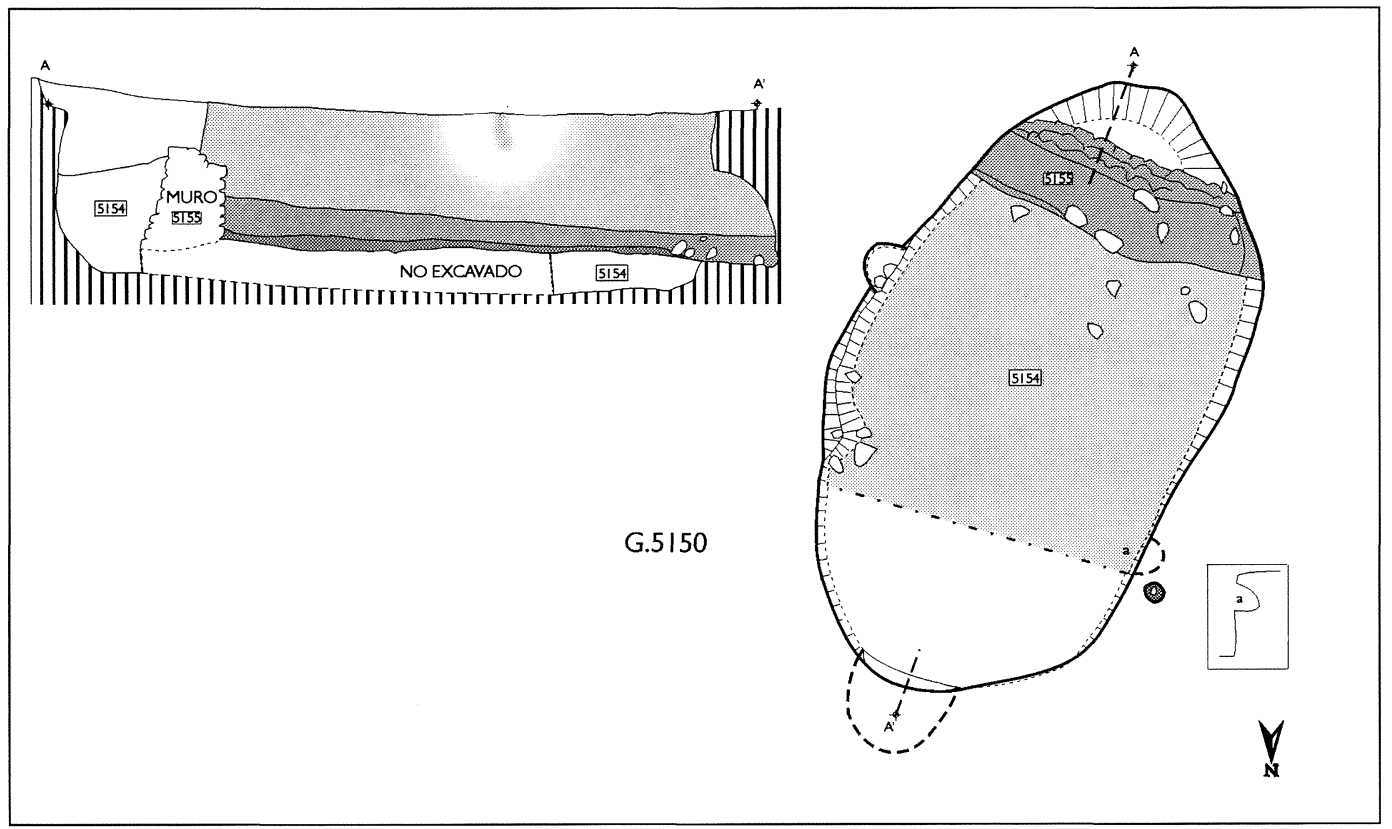

Fig. 9.-Planta y sección acumulativa de una cabaña del tipo A2. Escala 1/100.

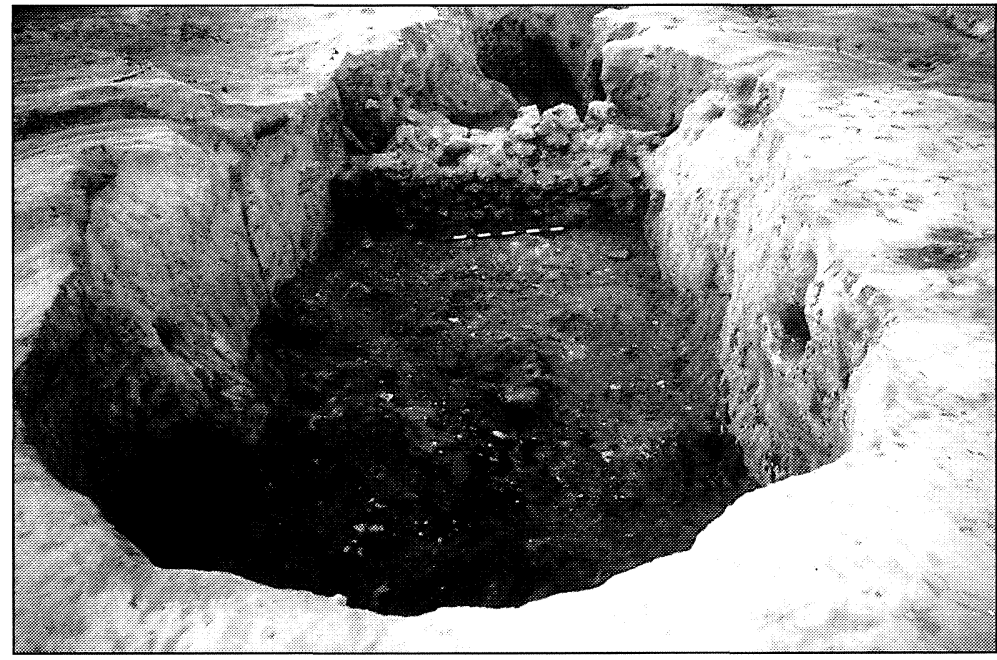

Fig. 10.-Cabaña del tipo A2 (UE 5150).

las grandes agrupaciones de estructuras definidas en la parte excavada del poblado.

\section{CUADRO ESQUEMÁTICO DEL TIPO A2}

\begin{tabular}{|c|c|c|c|}
\hline Identif. & Fase & Dimensiones & Observaciones \\
\hline L.6307 & ss. VI-VIII & $5.6 \times 2,2 \mathrm{~m}$. & Posible cabaña Al doble \\
\hline G.5640 & & $10,9 \times 3,85 \mathrm{~m}$. & Parcialmente excavada \\
\hline G.5150 & Ia & $6,65 \times 3,65 \mathrm{~m}$ & $\begin{array}{l}\text { Muro interno; pavimen- } \\
\text { tación }\end{array}$ \\
\hline G.5453 & II & $5,2 \times 2,85 \mathrm{~m}$. & \\
\hline G.5084 & $\mathrm{Ia} / \mathrm{Ib}$ & $\begin{array}{l}7,8 \times 3,8 / 4,55 \mathrm{~m} . \\
\text { (aprox.) }\end{array}$ & Parcialmente excavada \\
\hline
\end{tabular}

Cabañas de planta cuadrangular. Tipo B

El rasgo más característico de estas cabañas es su conformación restringida a un formato cuadrangular. La muestra disponible se reduce a 19 ejemplos, y la variabilidad de formatos es bastante más reducida que en el tipo A. La reconstrucción más plausible de la parte aérea de estos tipos ofrecería una cubierta vegetal o de madera a dos aguas (el registro arqueológico indica que no se emplearon materiales cerámicos). No se dispone de pruebas suficientes para proponer la clase de material o técnica constructiva empleada en la construcción de las paredes.

El repertorio lo componen tres ejemplos de La Indiana y dieciséis de Gózquez de Arriba. Los tres subtipos propuestos a continuación pueden englobarse en la definición clásica de quadratische Grubenhaüser (Donat, 1980: 57-62). El citado autor señala que el tipo se disemina por Centroeuropa entre los siglos VI y VIII, aunque también se conocen ejemplos datados en el v. Las dimensiones medias oscilan en los ejemplos centroeuropeos entre los 12 y 

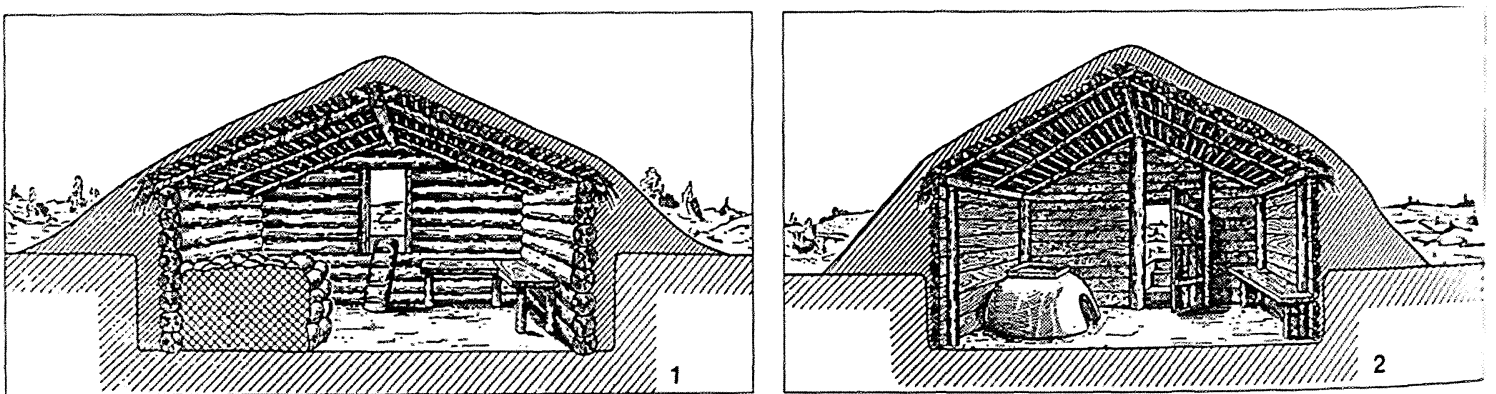

Fig. 11.-Cabañas rusas con paredes construidas con troncos (1) y tablones (2). Tomado de Milosevic, $1998:$ fig. 178.

$16 \mathrm{~m}^{2}$, aunque hay casos entre 9 y $25 \mathrm{~m}^{2}$. Parece razonable suponer que los modelos originarios de estos tipos de planta cuadrangular fueran construcciones de troncos o tablones de madera (fig. 11).

Una diferencia notable de la muestra madrileña respecto a las características de lo publicado en Francia o Inglaterra radica en la muy frecuente asociación de cabañas y estructuras de fuego (sobre todo hornos), que aproximaría nuestro conjunto a lo documentado en las regiones eslavas de Europa.

\section{Tipo BI (figs. 12 y 13)}

Las cuatro cabañas características de este grupo (todas ellas de Gózquez) tienen una planta estric-
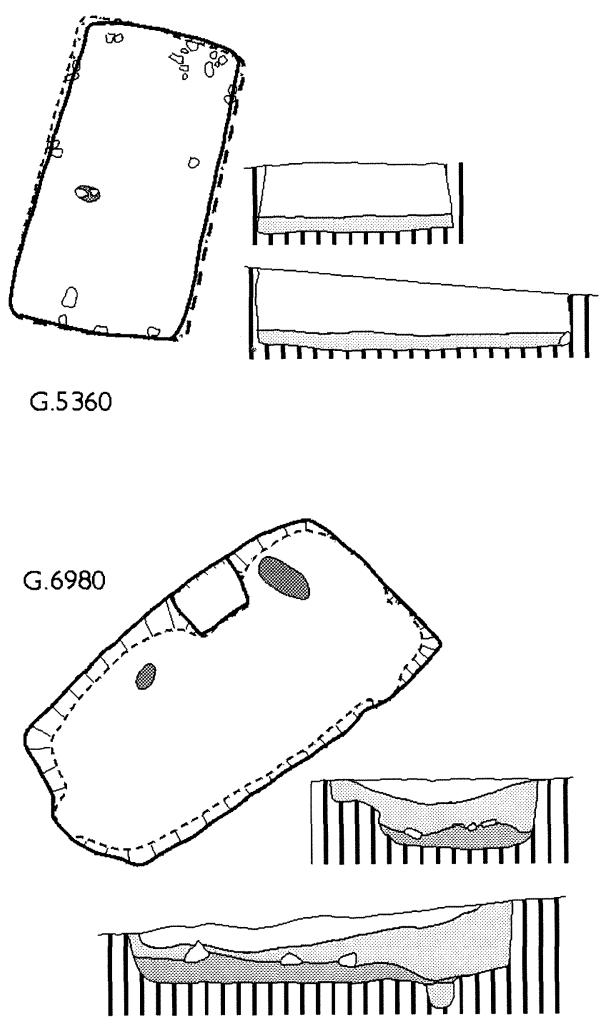
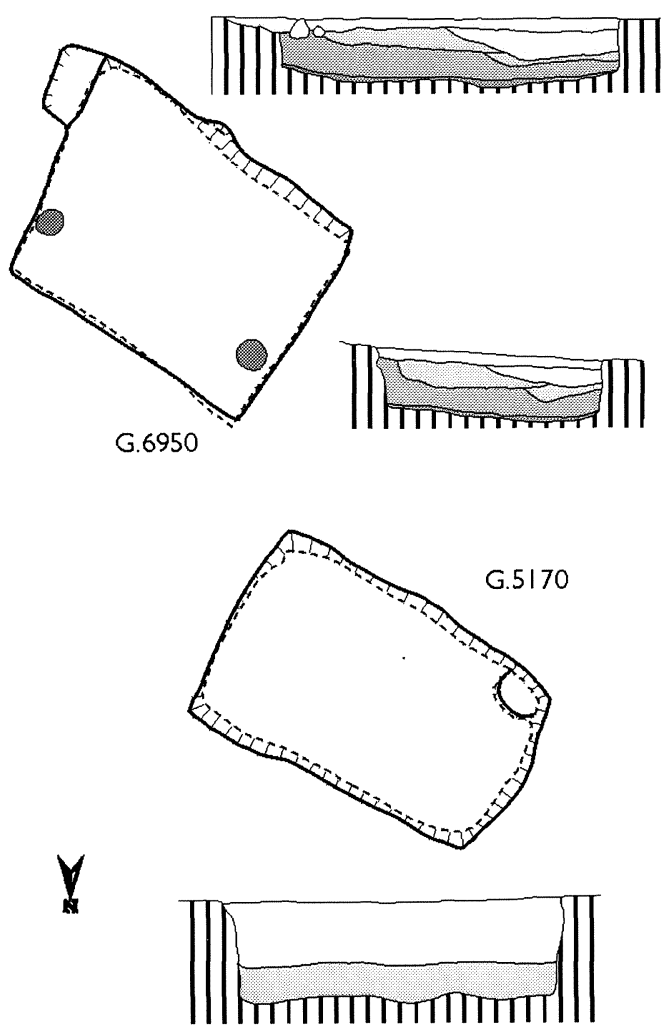

Fig. 12.-Plantas finales y secciones de cabañas del tipo B1. Escala 1/100. 


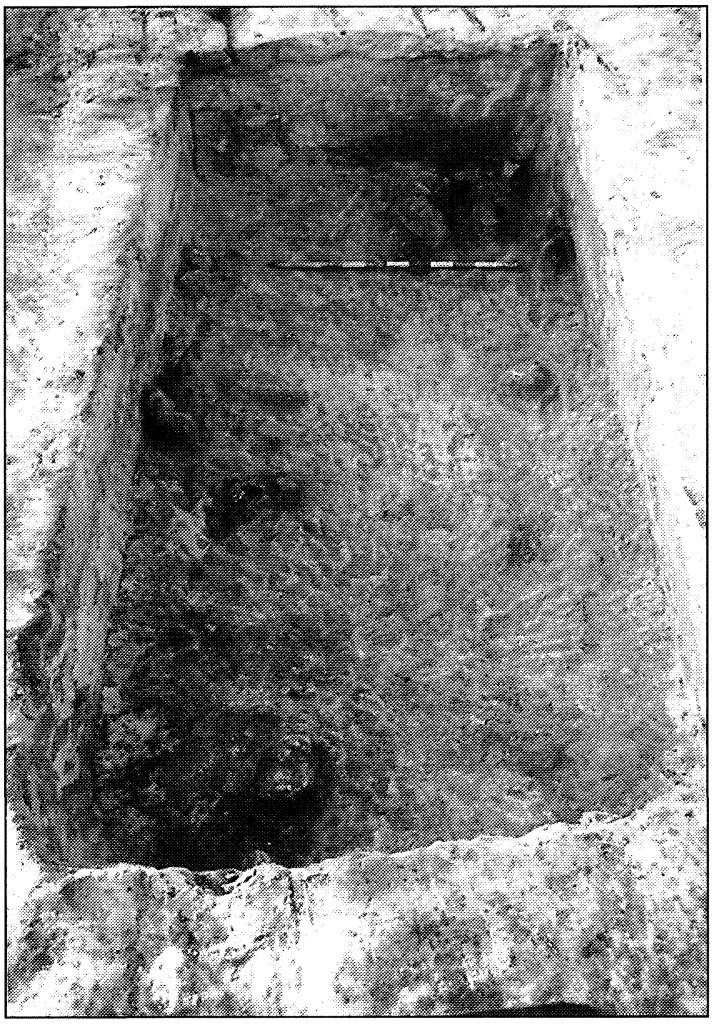

Fig. 13.-Cabaña del tipo B1 (UE 5360).

tamente rectangular, las esquinas en ángulos vivos y unas dimensiones de entre 5,7 y $8,5 \mathrm{~m}^{2}$. En sección, las paredes del hoyo son casi verticales o incluso algo reentrantes. En dos casos (G.6980 y G.5170) se han documentado pequeños bancos a media altura del hoyo en una esquina o en el centro de uno de sus lados largos septentrionales, que pudieron haber servido de apoyo a la solera de pequeños hornos internos o como escalón de acceso al fondo de la estructura. En ningún caso se observaron indicios de una preparación especial del suelo, que sin embargo es netamente horizontal. Las huellas de poste documentadas son bastante variables, poco profundas o pueden no aparecer (desde el modelo de dos postes, uno a cada extremo de su línea axial, a casos aparentemente asimétricos). En un ejemplo (G.6950) se documenta una rampa o escalón de acceso al fondo, muy similar al documentado en otras cabañas europeas (Donat, 1980: fig. 17-1; Milosevic, 1998: figs. 62, 171 y 215). La orientación de estas cabañas respeta una alineación ESE-ONO o NNE-SSO salvo en el caso de G.6980 (SO-NE).

Las cabañas del tipo B1 no aparecen en el último periodo de ocupación (III) del yacimiento de Gózquez (vid. infra: apartado 5), con lo cual, su datación quedaría restringida al siglo vi y a los dos primeros tercios del viI.

CUADRO ESQUEMÁTICO DEL TIPO B1

\begin{tabular}{|c|c|c|c|}
\hline Identif. & Fase & Dimensiones & Observaciones \\
\hline G.5360 & Ib & $3,18 \times 1,78 \mathrm{~m} .5,70 \mathrm{~m}^{2}$ & \\
G.6950 & Ib & $3,02 \times 2,32 \mathrm{~m} .7 \mathrm{~m}^{2}$ & \\
G.6980 & II & $3,96 \times 2,16 \mathrm{~m} .8,5 \mathrm{~m}^{2}$ & \\
G.5170 & Ib & $3,42 \times 2,10 \mathrm{~m} .7,2 \mathrm{~m}^{2}$ & \\
\hline
\end{tabular}

Tipo B2 (fig. 14)

Las cabañas de este grupo se caracterizan por una planta de forma más o menos cuadrangular (o subrectangular), si bien las esquinas son redondeadas intencionadamente (no a causa de un desgaste o deterioro de la estructura). Sus dimensiones son similares a las del grupo B1, aunque su frecuente asociación a hornos las aproxima al esquema general del tipo B3, del que las separa su tamaño, más reducido (entre 4,5 y $10 \mathrm{~m}^{2}$ ). Dos ejemplos proceden del yacimiento de La Indiana (L.4010 y L.2300) y ocho de Gózquez (G.5190, G.5280, G.6060, G.6550, G.6580, G.6730, G.6812 y G.6820).

Entre los diferentes ejemplos destaca la cabaña 2300 de La Indiana, con un agujero de poste en cada uno de los extremos de su eje longitudinal calzado reciamente con piedras dispuestas de canto, lo que indicaría una función sustentante inequívoca.

CUADRO ESQUEMÁTICO DEL TIPO B2

\begin{tabular}{|c|c|c|c|}
\hline Identif. & Fase & Dimensiones & Observaciones \\
\hline L. 4010 & ss. V-VI & $3,14 \times 2,84$ m. $8,9 \mathrm{~m}^{2}$ & $\begin{array}{l}\text { Huellas de postes axiales } \\
\text { (2) }\end{array}$ \\
\hline L. 2300 & ss. VI-VII & $3,30 \times 3,06 \mathrm{~m} .10 \mathrm{~m}^{2}$ & $\begin{array}{l}\text { Dos postes axiales cal- } \\
\text { zados }\end{array}$ \\
\hline G.5190 & III & $2,78 \times 1,6 \mathrm{~m} \cdot 4,4 \mathrm{~m}^{2}$ & $\begin{array}{l}\text { Planta irregular, postes } \\
\quad \text { axiales ( } 2)\end{array}$ \\
\hline G.5280 & II & $2,64 \times 2,08 \mathrm{~m} \cdot 5,5 \mathrm{~m}^{2}$ & Muy arrasada \\
\hline G.6060 & $?$ & $3,02 \times 2,26 \mathrm{~m} .6,8 \mathrm{~m}^{2}$ & Muy arrasada \\
\hline G.6550 & $\mathrm{Ib}$ & $3,50 \times 2,16 \mathrm{~m} \cdot 7,5 \mathrm{~m}^{2}$ & Asociada a horno \\
\hline G.6730 & III & $3,02 \times 2,10 \cdot 6,3 \mathrm{~m}^{2}$ & $\begin{array}{l}\text { Muy arrasada. Nicho la- } \\
\text { teral }\end{array}$ \\
\hline G.6812 & II & $2,5 \times 1,8 \mathrm{~m} \cdot 4,5 \mathrm{~m}^{2}$ & $\begin{array}{l}\text { Postes axiales (2), ni- } \\
\quad \text { chos }(2)\end{array}$ \\
\hline G.6820 & Ia & $2,88 \times 1,80 \mathrm{~m} .5,2 \mathrm{~m}^{2}$ & Una huella de poste \\
\hline G.6580 & $\mathrm{Ib}$ & $2,88 \times 2,15 \mathrm{~m} \cdot 6,2 \mathrm{~m}^{2}$ & Asociada a horno \\
\hline
\end{tabular}

Tipo B3 (fig. 15 y 16)

Las cabañas del tipo B3 adoptan en planta una forma claramente rectangular, con sus esquinas en ángulos más o menos rectos o ligeramente redondeados. Se distinguen del resto por sus amplias dimensiones (entre 12 y $17 \mathrm{~m}^{2}$ de espacio interior 


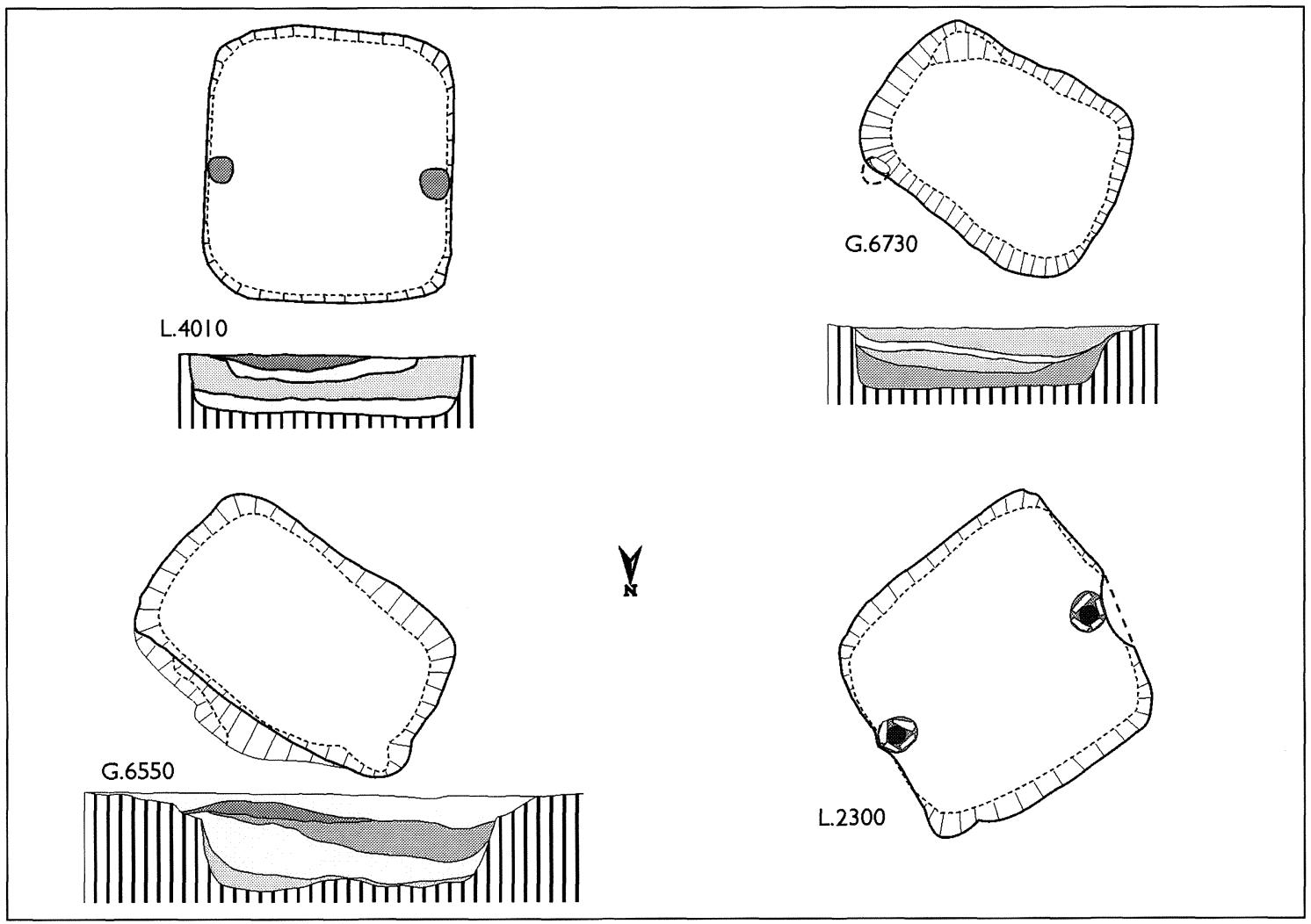

Fig. 14. - Plantas y secciones de cabañas del tipo B2. Escala 1/100.

útil). Suelen contar con hornos exteriores adosados y presentan con frecuencia huellas claras de postes (en número variable) a lo largo de su eje largo o en las esquinas ${ }^{14}$. Cuatro de ellas (G.5555, G.6590, G.6090 y L.2150) permiten fijar las características del tipo, al que podrían adscribirse otros dos ejemplos de más difícil interpretación debido a su estado de conservación (G.6940 y G.6873).

$\mathrm{Su}$ orientación es constante con ligeras variaciones, de modo que su eje largo se dispone en dirección noroeste-sudeste. Los hornos se adosan por el exterior cerca del extremo de uno de sus lados largos (figs. 17 y 18). Además, algunos indicios probarían la existencia de zonas internas de hogar o fuego (en el centro de la pared meridional de 6590 y en la esquina sudeste de 5555). Tres cabañas res-

${ }^{14}$ Los agujeros de poste en forma de pipa, presentes en alguna de estas cabañas, serían un indicador de que su abandono se produjo repentinamente, por ruina, mientras que otras huellas de poste de planta circular podrían señalar un desmantelamiento de la estructura y de sus partes sustentantes. Estos aspectos y otros relacionados con la vida media de esta clase de estructuras (unos 30 años) se tratan en la memoria-resumen del yacimiento de West Heslerton (Powlesland, 1998: 3-6-1). ponden estrictamente a los criterios expuestos, aunque otros tres casos podrían ser asimilados al mismo (G.6940, L.5286 y G.6873).

\section{CUADRO ESQUEMATICO DEL TIPO B3}

\begin{tabular}{|c|c|c|c|}
\hline Identif. & Fase & Dimensiones & Observaciones \\
\hline G.6090 & $\mathrm{Ib}$ & $4,60 \times 3,00 \mathrm{~m} \cdot 13,80 \mathrm{~m}^{2}$ & Exenta. Horno ext. \\
\hline G.6940 & II & $?$ & Deteriorado \\
\hline G.6590 & $\mathrm{Ib}$ & $4,54 \times 2,64 \mathrm{~m} .12 \mathrm{~m}^{2}$ & Exenta. Horno ext. \\
\hline G.5555 & $\mathrm{Ib}$ & $5,00 \times 2,66 \mathrm{~m} \cdot 13,30 \mathrm{~m}^{2}$ & $\begin{array}{l}\text { Forma complejo con } \\
\text { otras estructuras. Horno }\end{array}$ \\
\hline G.6873 & & $?$ & $\begin{array}{l}\text { ext., hogar int. Postes } \\
\text { Muy deteriorada }\end{array}$ \\
\hline L. 2150 & ss. VI-VII & $4,90 \times 3,40 \mathrm{~m} \cdot 16,7 \mathrm{~m}^{2}$ & $\begin{array}{l}\text { Exenta. Postes en es- } \\
\text { quinas }\end{array}$ \\
\hline
\end{tabular}

\section{DATACIÓN Y PERIODIZACIÓN}

La datación de todas las estructuras anteriormente expuestas queda fijada por unos límites bastante bien definidos por lo que respecta al yacimiento de Gózquez de Arriba. El análisis del material cerámico (autóctono o importado) combinado con el exa- 


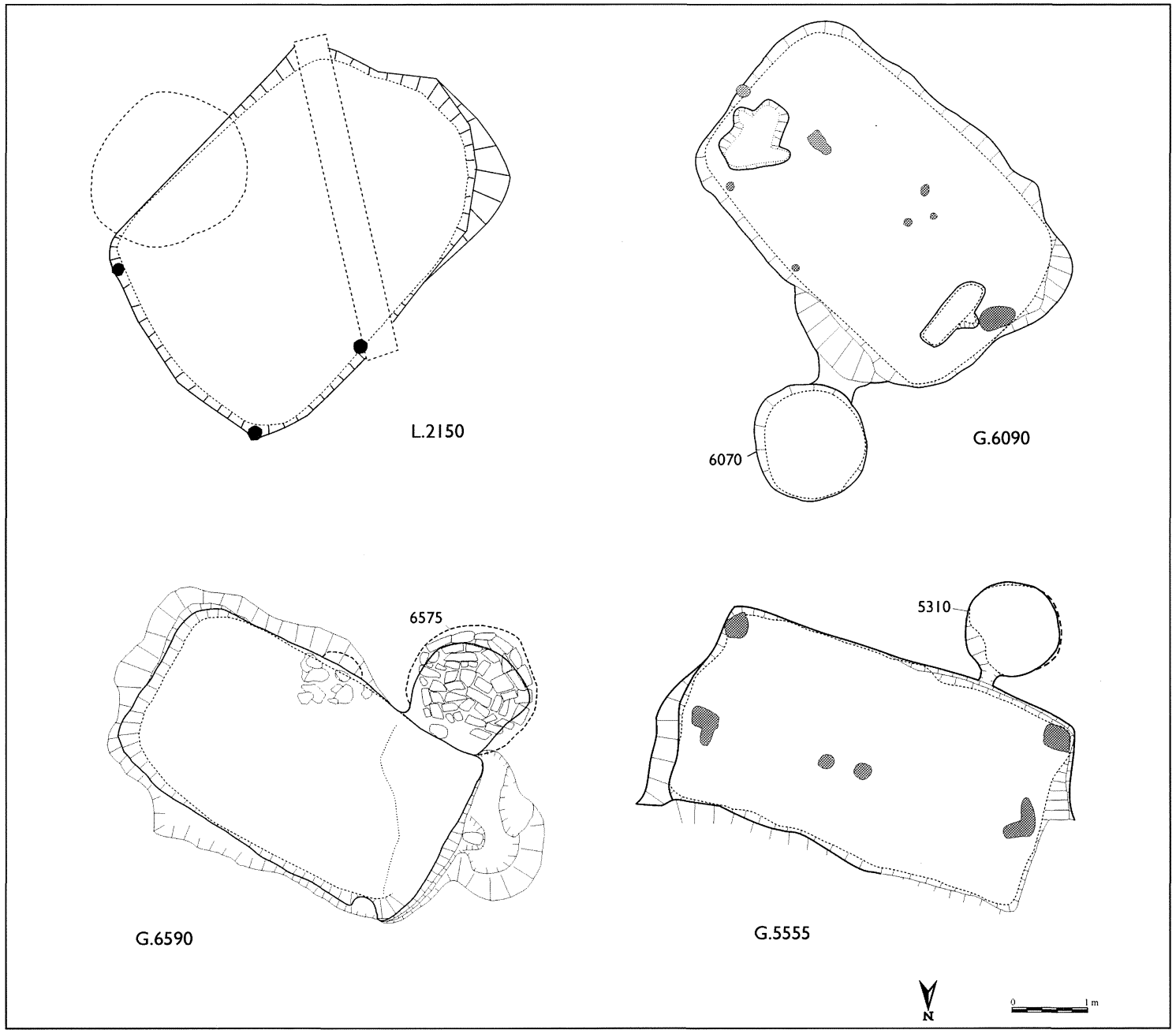

Fig. 15.-Planta de varias cabañas del tipo B3. Escala 1/100.

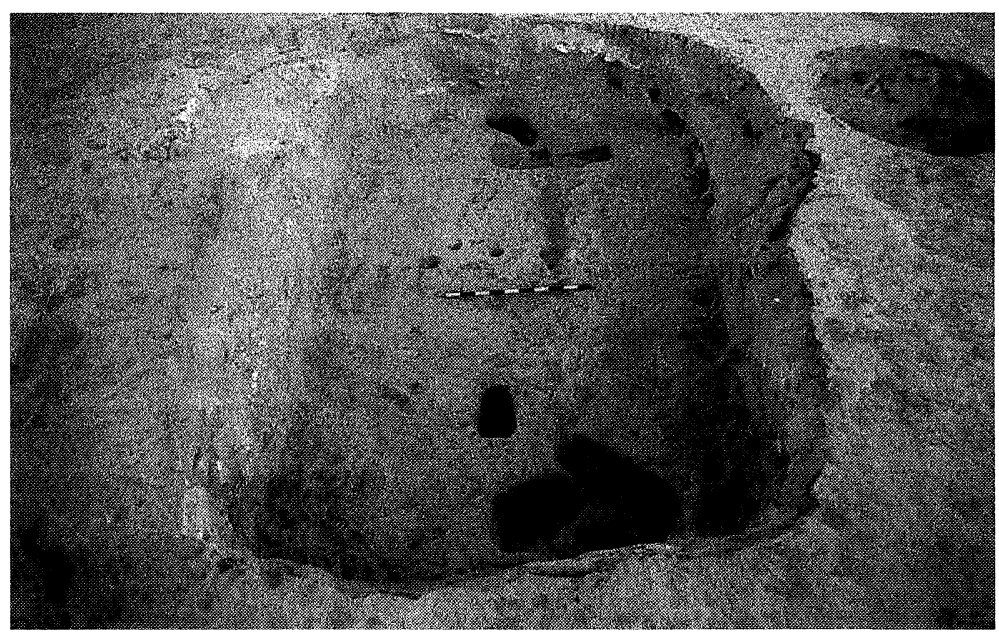

Fig. 16.-Cabaña del tipo B3 (UE 6090). Al fondo (derecha) se observa la huella del horno. men exhaustivo de todas las relaciones estratigráficas documentadas entre contextos cerrados y los resultados de una serie de dataciones radiocarbónicas permiten proponer un periodo de ocupación cuyo inicio quedaría situado a principios del siglo vi mientras que el abandono habría tenido lugar a finales del siglo viII. Dentro de este marco cronológico, han podido diferenciarse cuatro periodos de ocupación (denominados Ia, Ib, II y III) correspondientes a otros tantos modelos de conjuntos cerámicos que responden a una evolución y transformación de los ajuares domésticos a lo largo de 
tres siglos ${ }^{15}$. En espera de los resultados de los análisis de $\mathrm{C} 14$ de un más amplio lote de muestras, una datación estimativa para estas cuatro fases sería la siguiente: periodo Ia (primera mitad del s. vI), periodo Ib (segunda mitad del s. VI), periodo II (primera mitad del s. viI) y periodo III (segunda mitad del s. vII y s. VIII).

Conscientes de lo arriesgado de esta propuesta, las referencias calendáricas anteriores han de entenderse exclusivamente en un sentido amplio u orientativo. Las diferencias establecidas entre los cuatro modelos cerámicos correspondientes a cada uno de los periodos son arbitrarias (existe todo un margen de indeterminación que afecta a contextos que suponen eslabones entre periodos contiguos), pero cuantificables y estrictas en cuanto que se refieren a la presencia/ausencia de determinadas producciones dentro de muestras amplias pertenecientes a contextos cerrados y a la representación proporcional de unos tipos de cerámicas respecto a otros. Se ha verificado a posteriori la inexistencia de contradicciones entre la periodización propuesta y la estratigrafía entre todos los contextos que ofrecían relaciones directas.

Como veremos, las diferencias resultan fáciles de establecer entre los conjuntos pertenecientes al primero de los periodos

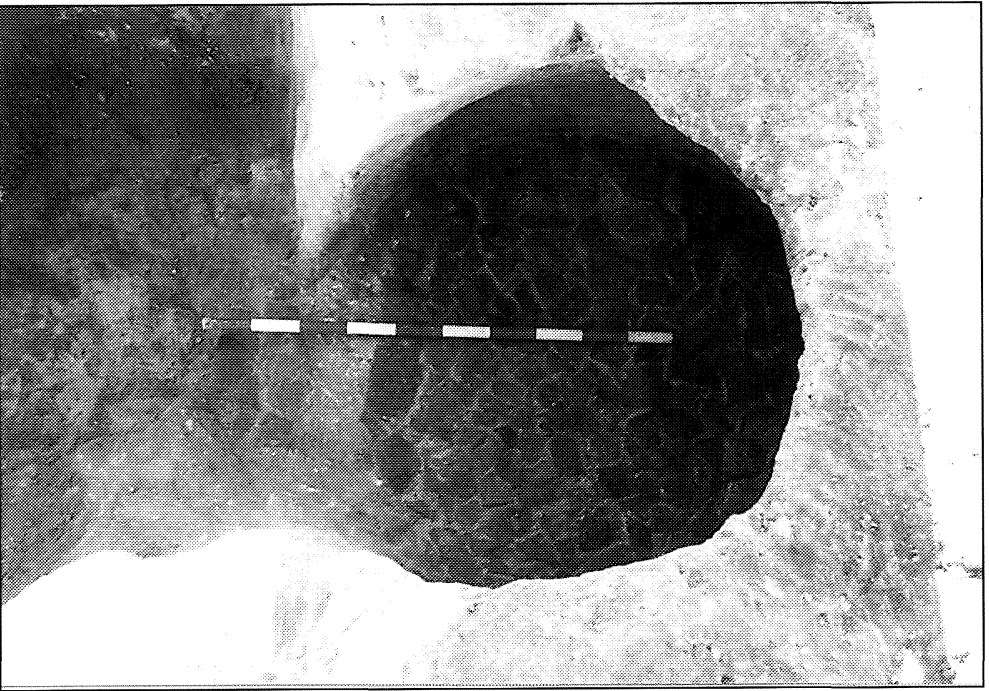

Fig. 17.-Detalle del horno 5204 con solera de fragmentos cerámicos (UE 5380). Su utilización se llevó a cabo desde el interior de la cabaña 5200.

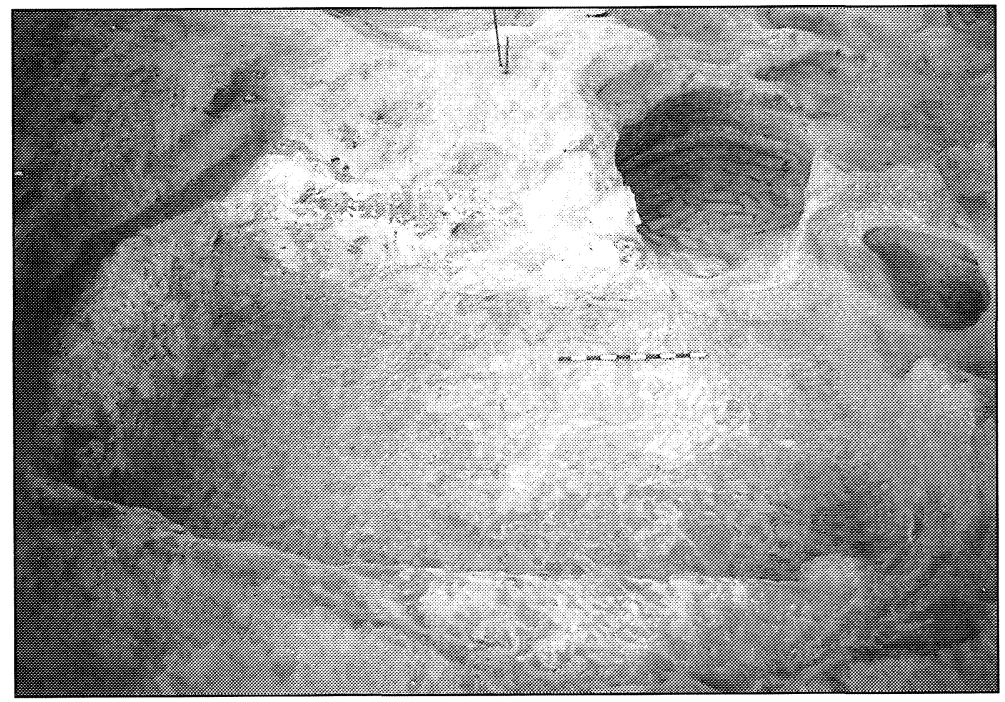

Fig. 18.-Cabaña del tipo B3 (UE 6590) asociada a un horno con solera de tejas. respecto a los dos últimos, incluso son nítidas entre el Ia y el Ib; la discriminación es más compleja entre el Ib y el II, ya que depende de la representación proporcional de una clase cerámica y de la ausencia de otra; y el periodo III posee, por una parte, características cercanas a los conjuntos del II, y por otra, una variabilidad interna que sólo es posible resolver

\footnotetext{
15 Para una descripción preliminar de estos conjuntos cerámicos véase Vigil-Escalera, e.p. A modo de síntesis, las diferentes clases cerámicas definidas responden a un doble discriminante: técnico (factura o tipo de modelado) y características de la pasta (mediante un análisis macroscópico de componentes y granulometría).
}

merced a ciertos rasgos peculiares de la morfología de la clase cerámica dominante (y casi exclusiva).

La datación del periodo Ia combina una edad radiocarbónica en torno al segundo cuarto del siglo $\mathrm{VI}^{16}$ (fecha de los materiales de relleno, en concreto hueso, incluidos en los niveles que suponen la amortización de la estructura G.5075-76) con uno de los únicos materiales importados catalogable con segu-

16 BETA-135020. Edad convencional 1540 \pm 50 BP, calibrada a 1 sigma en $440 / 585$ (68\% de probabilidad) y en $415 /$ 630 a 2 sigma (95\% de probabilidad). El cruce de la edad radiocarbónica de la muestra con la curva de calibración está en el año 540 


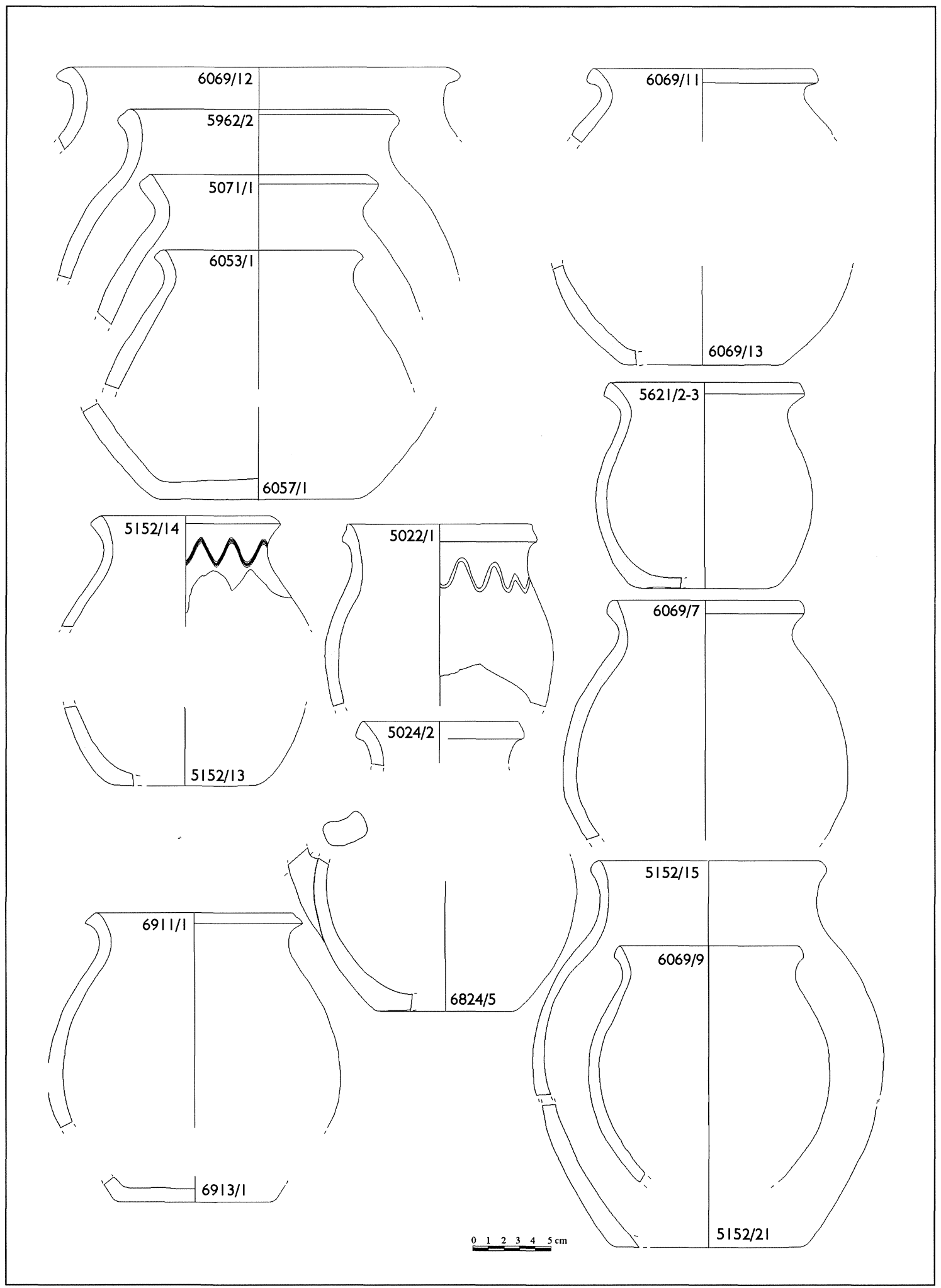

Fig. 19.-Clase cerámica TL1. 


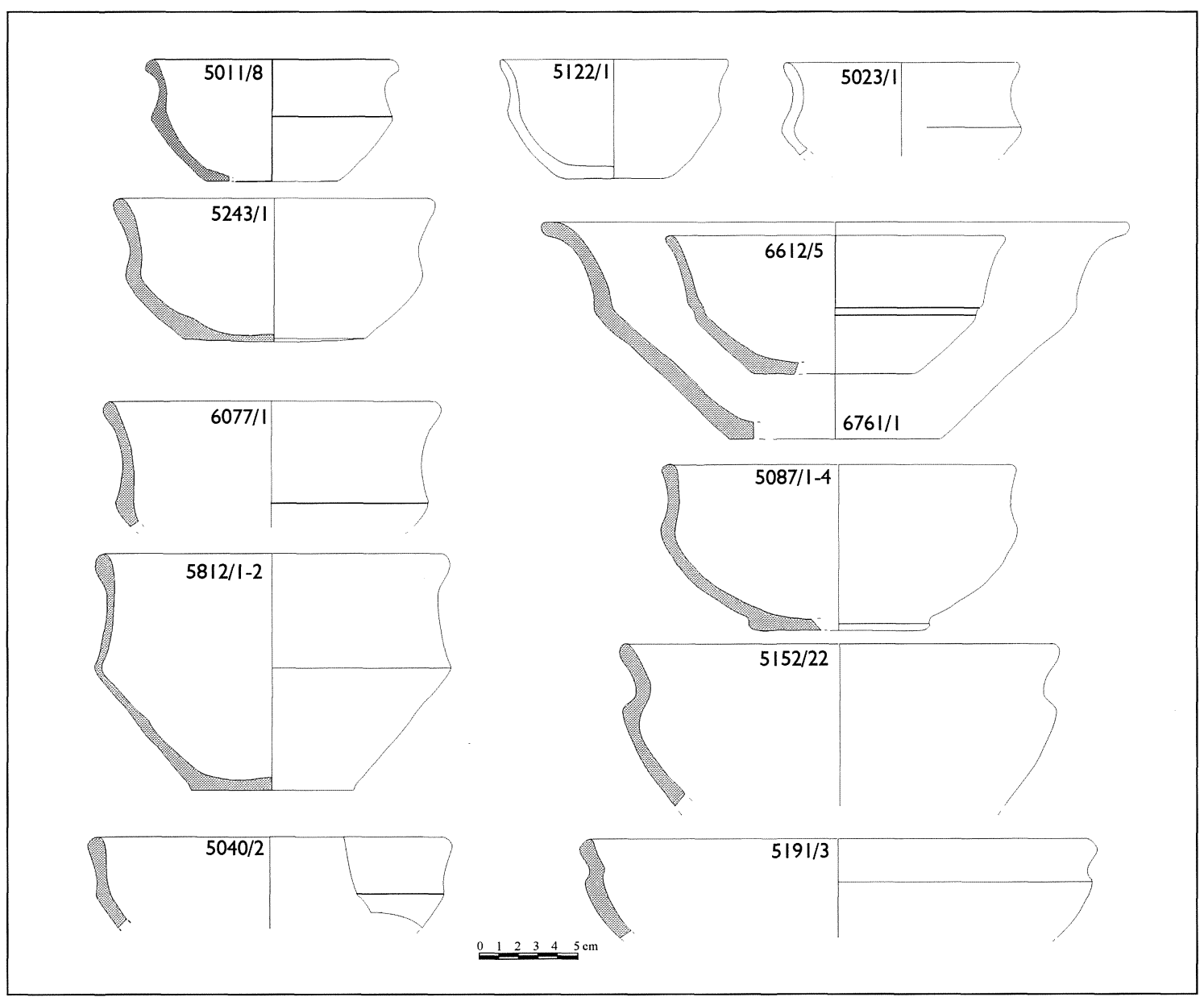

Fig. 20.-Diversos morfotipos de cuencos carenados de cerámica común a torno rápido. Desde el inicio coexisten modelos con superficies bruñidas negras $(6612 / 5,6761 / 1)$ y tipos sin tratamiento exterior alguno. A partir del periodo Ib/II, los perfiles se hacen más redondeados y laś formas más abiertas y planas $(5191 / 3,5040 / 2)$, alejándose de los tipos clásicos, representados por 5011/8 ó 6077/1. Existen versiones modeladas a mano o torneta en contextos de los periodos Ia y Ib (5122/1 y 5023/1).

ridad (un cuenco de TSA de la forma Hayes $99^{17}$ ) y un lote de vasos muy homogéneo en el que las producciones a torno lento TL1 (ollas) y rápido TR3 (ollas y cuencos) y TR2 (jarros) ofrecen unos rasgos muy peculiares (figs. 19 a 21). Es significativa también la práctica ausencia de T.S. Hispánica Tardía ${ }^{18}$

17 La cronología clásica de la forma Hayes 99 oscila entre 510-540 para la variante A y 530-580 para la B (Hayes, 1972: 152-155), si bien existe controversia reciente al respecto (Ramon-Cau, 1997: 274).

${ }^{18}$ La T.S.H.T. representa menos del $0,5 \%$ en los contextos en los que aparece, posiblemente como material residual o fruto del coleccionismo (nueve fragmentos con un peso total de 80 gramos). Existe una representación global mucho más amplia, por ejemplo, de materiales residuales de época altoimperial romana o de cerámica prehistórica. El inventario completo del material cerámico del poblado ofrece un total de 14.383 fragmentos de cerámica para un peso total de más de $413 \mathrm{~kg}$. y de las producciones de T.S. Gris y Anaranjada, que, según las estratigrafías de la «Antiga Audiència» de Tarragona (Aquilué, 1993: 125) desaparecen a finales del siglo $v$ o inicios del vi.

El periodo Ib se caracteriza por la pervivencia del conjunto anterior junto a la aparición de un nuevo grupo de vasos a torno lento (TL2) que parece ir sustituyendo a la clase TL1 (ollas y jarros, sobre todo). También se consolidan producciones modeladas a mano (la clase TL5) que parecen tener un relativamente corto ciclo de uso, ya que desparecen de la escena en el periodo III. Las únicas formas documentadas de este tipo de cerámica de pasta arenosa modelada a mano (fig. 22) son varios cuencos, una tapadera discoidal decorada con ungulaciones y algunos platos o discos de gruesas paredes para cocer tortas de pan asimilables a la serie 8 de $\mathrm{S}$. Gutiérrez 


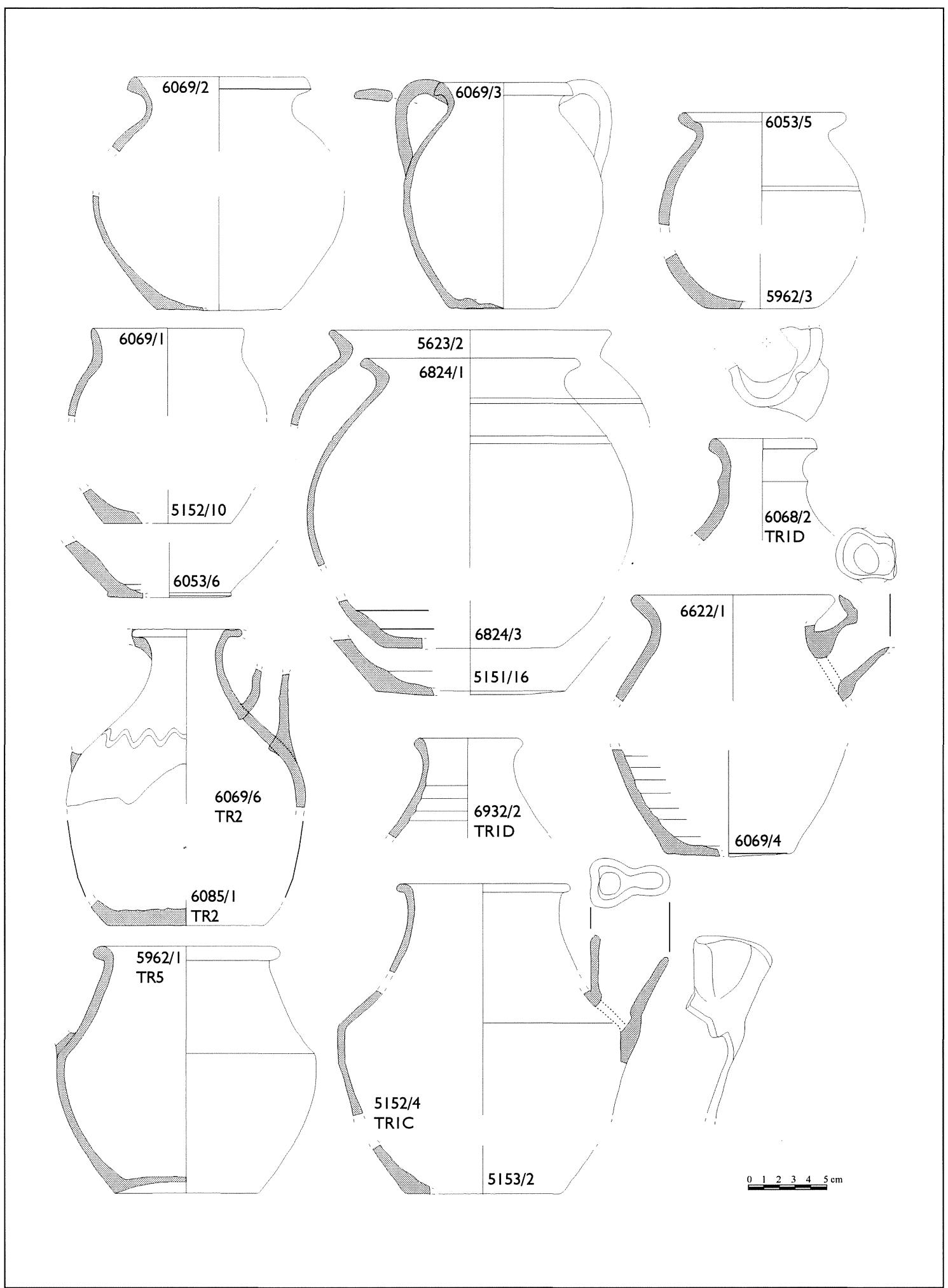

Fig. 21.-Tipos de ollas y jarros a torno rápido característicos de los periodos Ia y Ib. Todos son de la clase TR3 salvo que se especifique otra cosa. 


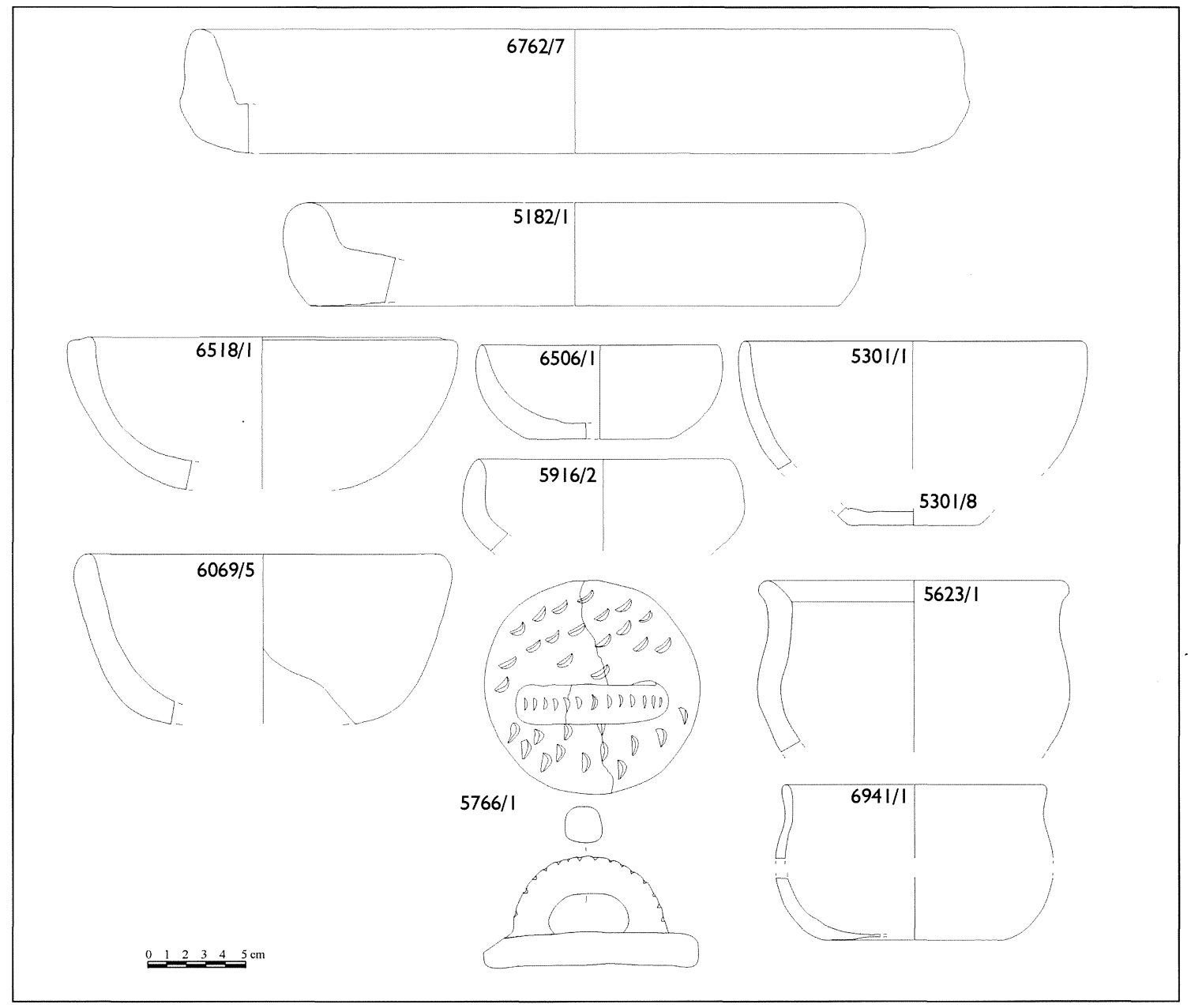

Fig. 22.-Cerámicas modeladas a mano de los periodos Ib y II.

(Gutiérrez, 1996: 84-85 y 139-140) ${ }^{19}$. También aparecen, y sólo en contextos de este periodo, algunos fragmentos de material anfórico, uno de ellos (aún por analizar) asimilable a un cierto tipo de spatheion (anforisco).

En los conjuntos correspondientes al periodo II ha desaparecido por completo la clase cerámica TL1 (a partir de ahora sólo aparece en forma de material residual y muy esporádico) y se reduce considerablemente el número de vasos realizados a torno rápido (su representación proporcional queda siempre por debajo del $15-20 \%$ respecto al total y no adscribible a las clases características del primer periodo), mientras aumenta la variedad morfotipológica de TL2, que alcanza y supera en representación numérica y de peso el $50 \%$ del total cerámico. Las formas

19 Esta misma forma aparece en Cartagena en contextos datados en el último cuarto del siglo vi y la primera mitad del vil (Laiz-Ruiz, 1988: 294-296). asignables a esta clase (figs. 23 y 24 ) son ollas de labio redondeado, jarros de borde trebolado, jarros con pitorro, cuencos, cazuelas y tinajas, sobre todo.

El periodo III conoce una sustancial reducción de la variedad de pastas y tipos, y el grupo de cerámicas TL2 (en el que aparecen vasos de bordes engrosados y un alto porcentaje de cerámica de almacenamiento) ocupa en torno a un $90 \%$ del total. En justicia, restaría por analizar separadamente los conjuntos cerámicos de contextos de este periodo para comprender su posible evolución, ya que es en éste en el que resulta más difícil distinguir la posible residualidad de clases cerámicas pertenecientes a periodos anteriores. La forma más característica de TL2 en el periodo III es una olla con el cuello resaltado del galbo mediante una ligera inflexión, provista de dos asas y con el labio engrosado y plano (fig. 25, pieza 6253/1), aunque también son peculiares algunos grandes contenedores (fig. 26). Entre las 


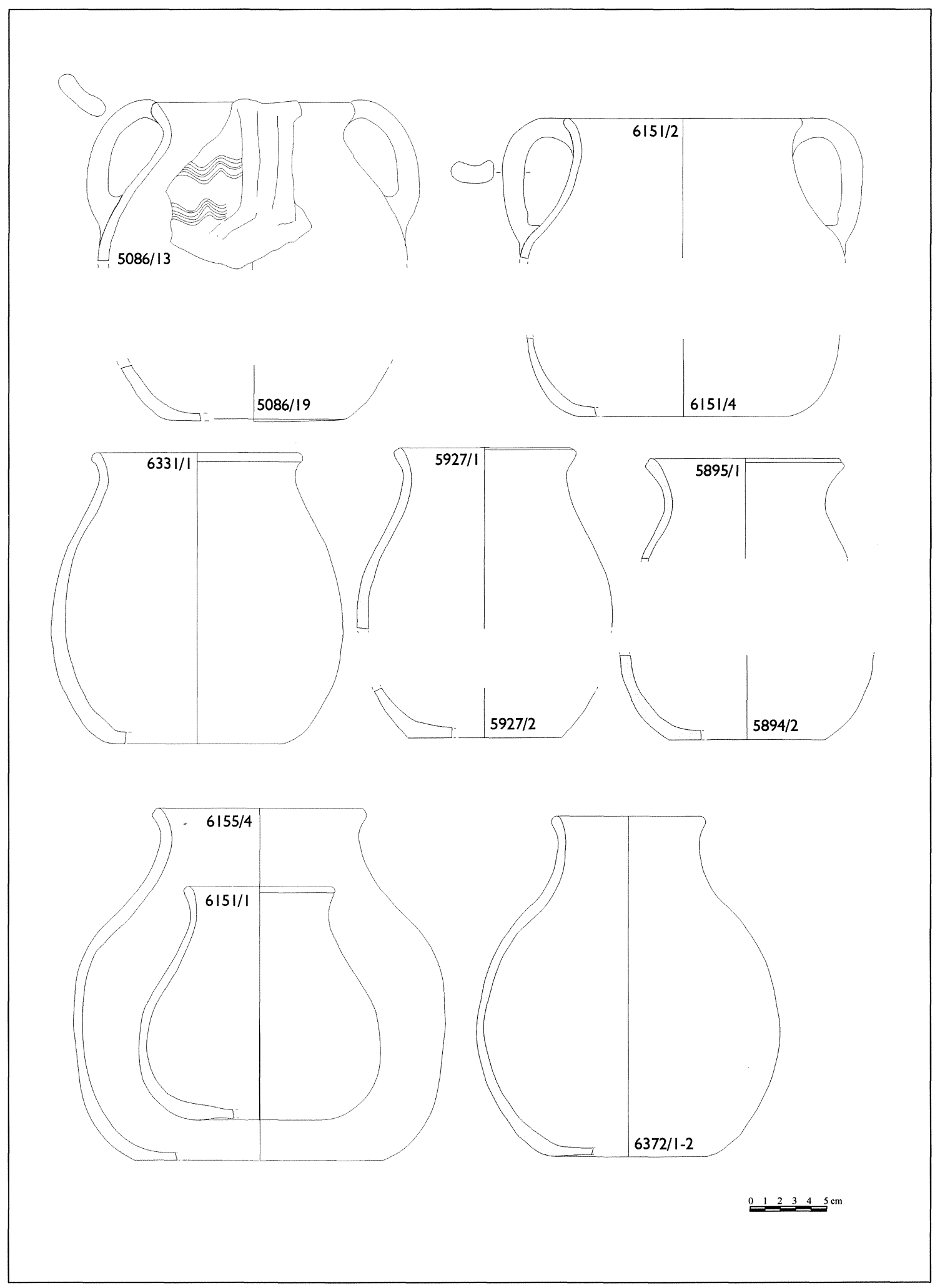

Fig. 23.-Formas cerradas de la clase TL2 (periodo II), excepto 6155/4 y 6151/1, 2 y 4 (periodo III). 


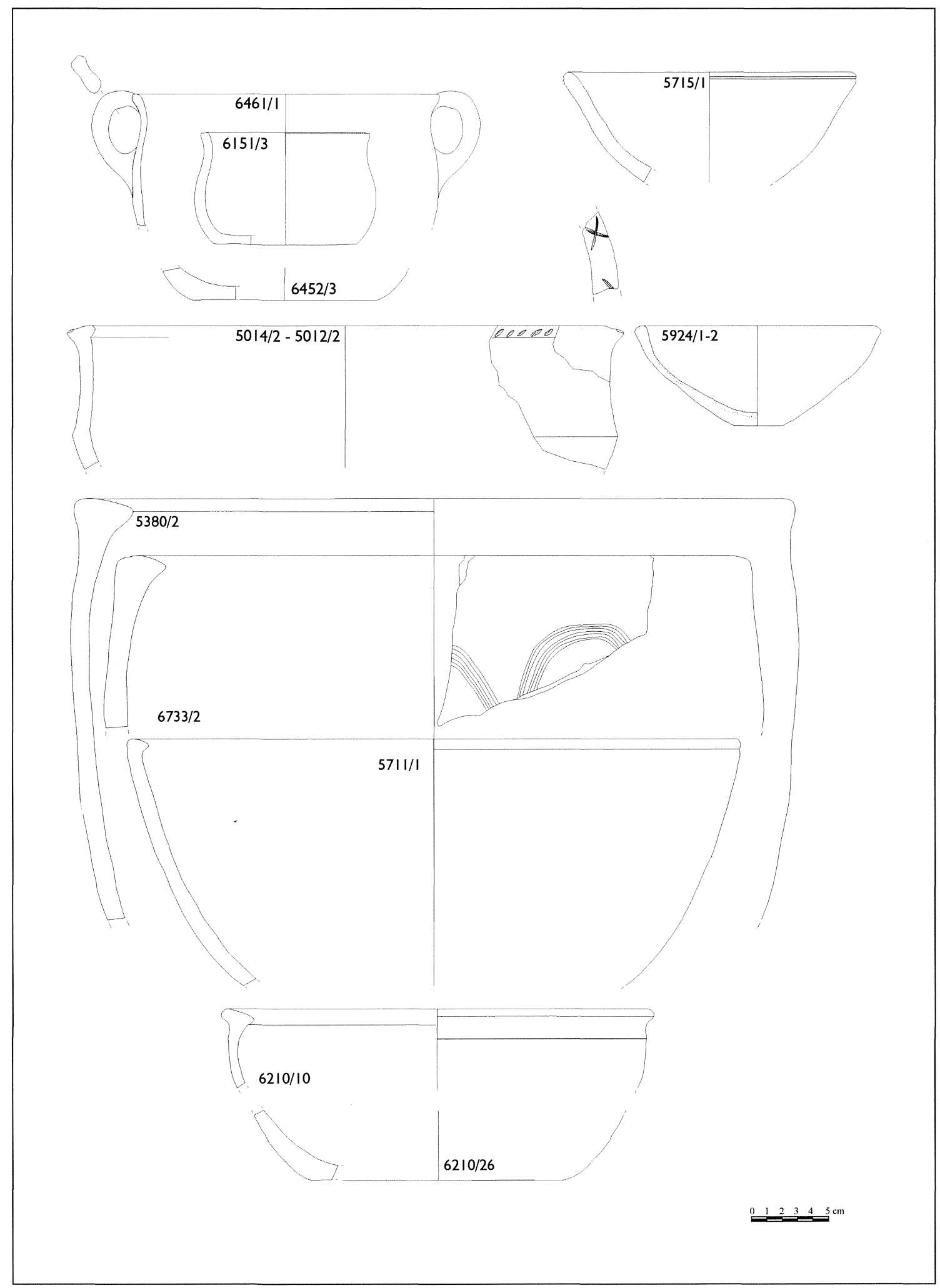

Fig. 24.-Formas abiertas de la clase TL2 (excepto 5014/2 y 5012/2, clase TL1) 


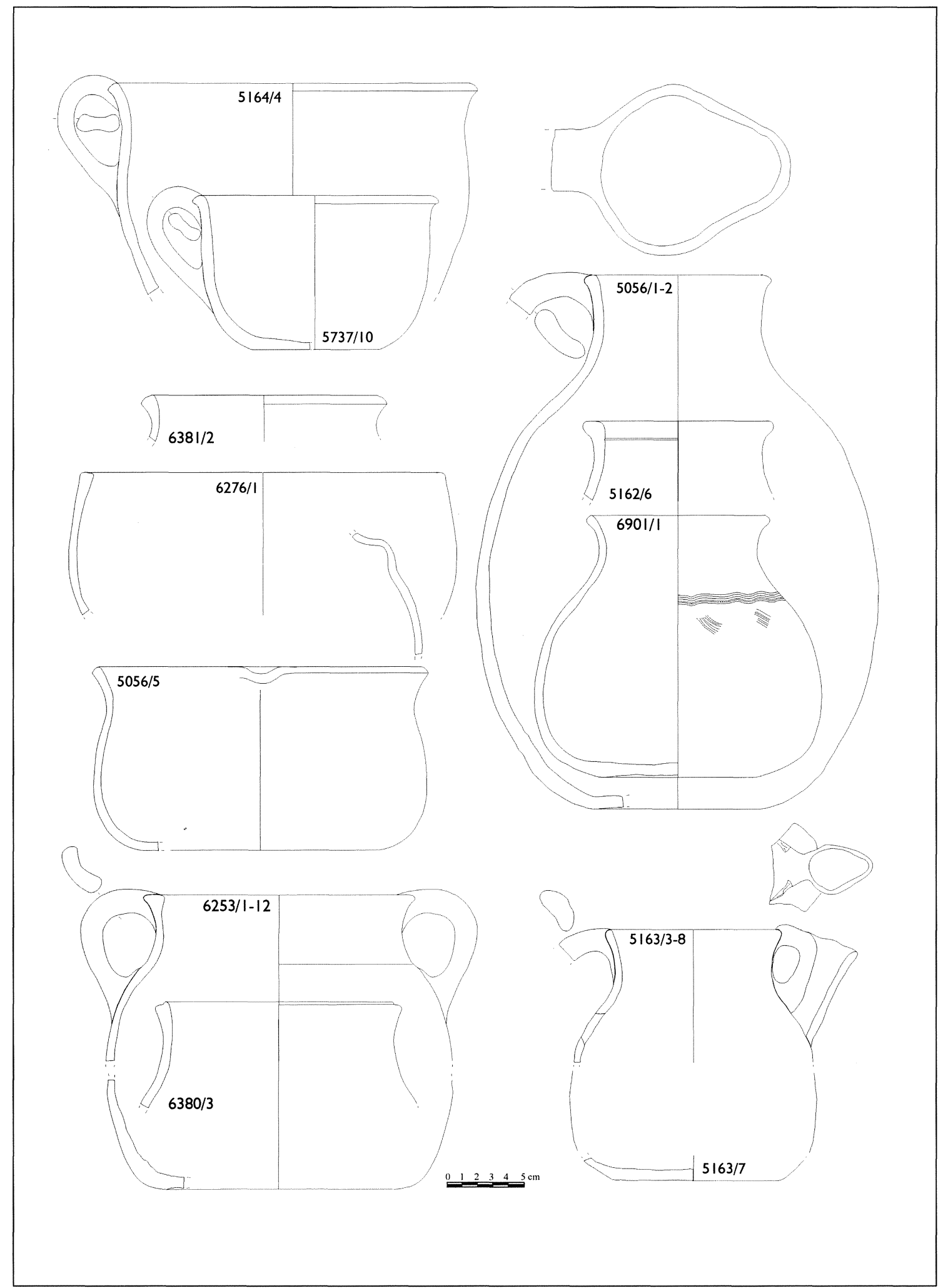

Fig. 25.-Algunas formas características de la clase TL2 (periodo III). 


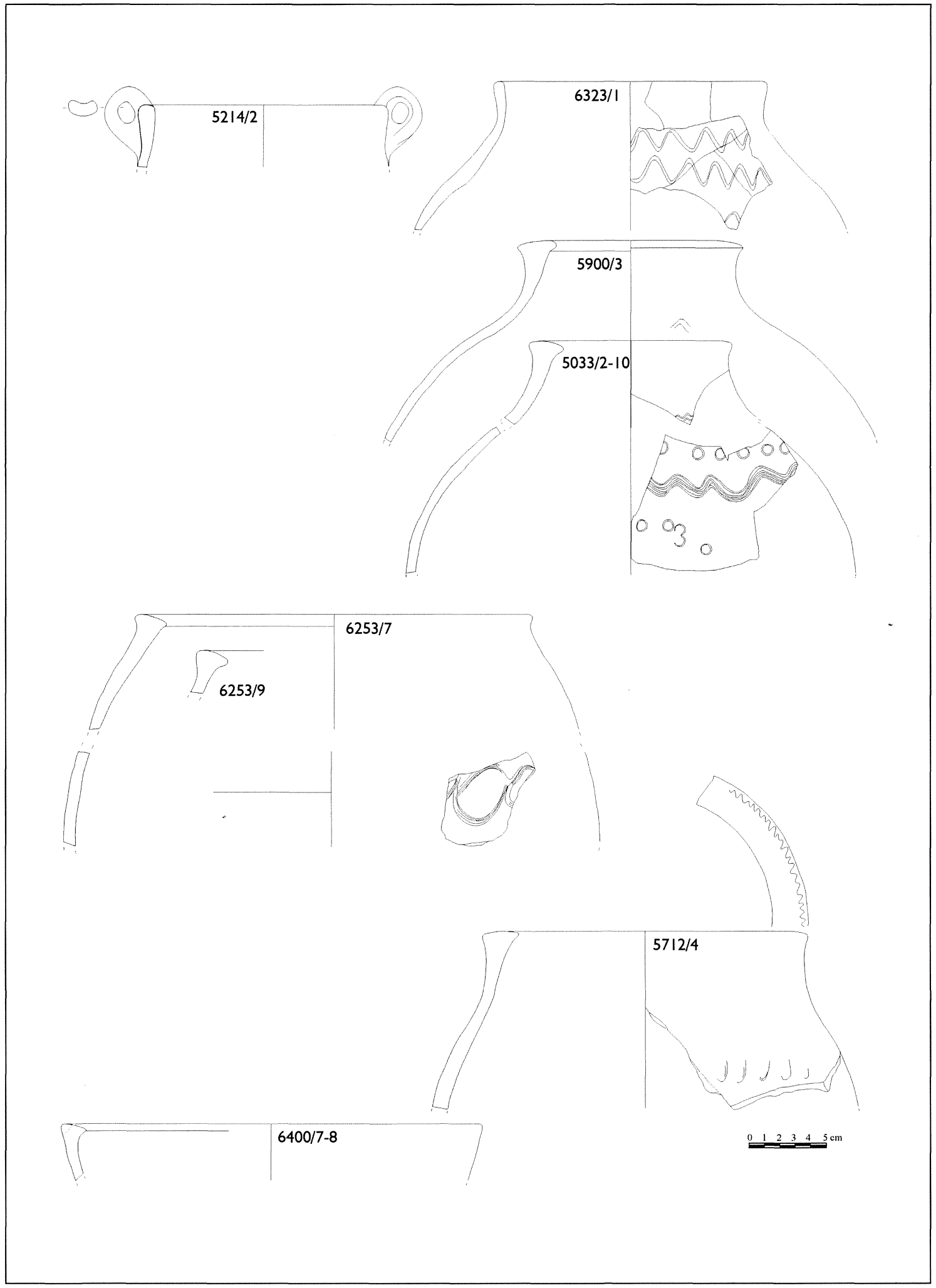

Fig. 26.-Algunas formas características de la clase TL2 (periodo III). 


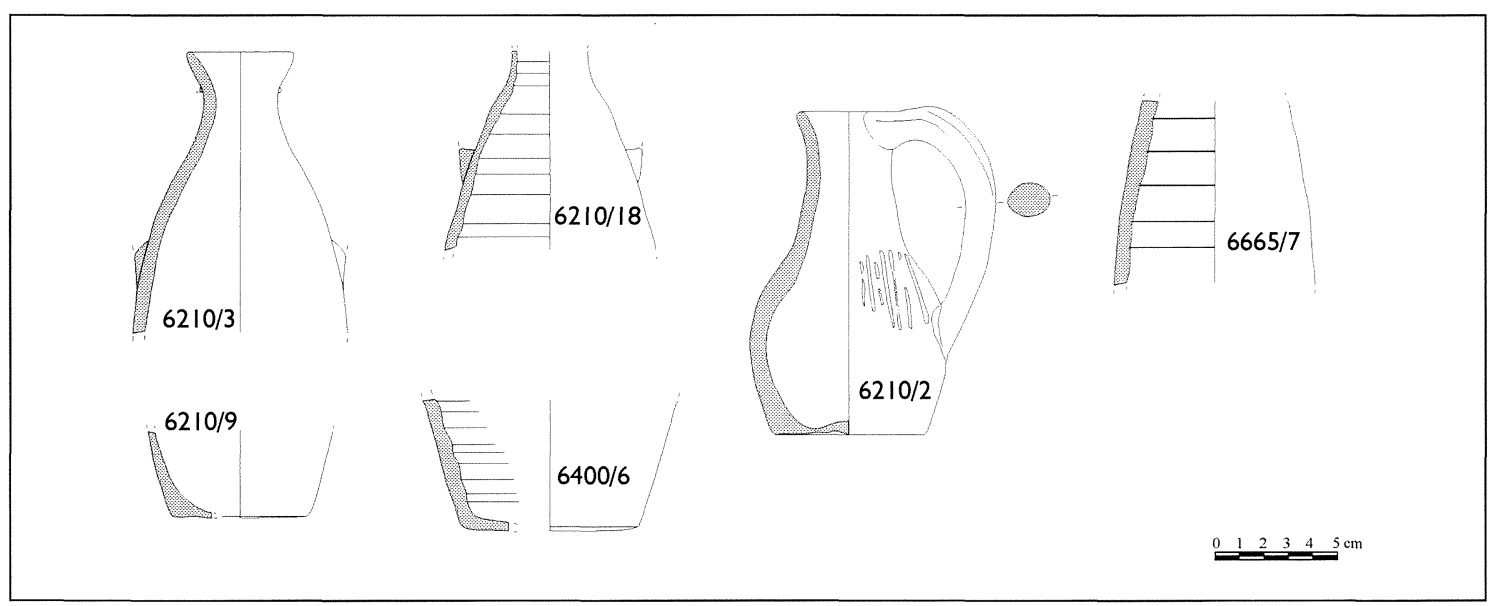

Fig. 27.-Algunas formas características a torno rápido del periodo III.

cerámicas a torno rápido supervivientes destaca la presencia de jarritas piriformes o globulares de pastas claras y finas de los tipos normalmente recuperados en las necrópolis consideradas visigodas (fig. 27). Las dataciones radiocarbónicas disponibles para contextos de este periodo ofrecen unos límites comprendidos entre mediados del s. vir y finales del VIII ${ }^{20}$. Otro nivel con un conjunto de cerámicas representativo de este periodo proporcionó el hallazgo de un broche de cinturón liriforme de bronce, material que cabría considerar representativo de la última fase de utilización de las necrópolis de «época visigoda».

La datación de las estructuras excavadas en los yacimientos de Pinto resulta, de momento, algo menos precisa que las del poblado de San Martín de la Vega. Las cabañas y sus estructuras relacionadas se situarían en las primeras fases de ocupación del sitio (segunda mitad del siglo $v$ a mediados del viII), aunque los límites de la frecuentación esporádica del área parecen prolongarse hasta finales del $x$ d.n.e. Los contextos de la primera ocupación aún cuentan con una cierta representación de T.S. hispánica tardía, mientras que las estructuras aisladas asignables a la frecuentación final de la zona ofrecen ya características islámicas claras (jarras de galbo estriado con pastas pajizas, aunque no apa-

${ }^{20}$ BETA-135022: edad convencional $1390 \pm 60$ BP, calibrada a 1 sigma en $625 / 675$ y en $560 / 720$ ó $745 / 760$ a 2 sigma; el cruce de la edad radiocarbónica de la muestra con la curva de calibración está en el año 655. BETA-135021: edad convencional $1210 \pm 50 \mathrm{BP}$, calibrada a 1 sigma en $765 / 885$ y en 685/965 a 2 sigma; el cruce de la edad radiocarbónica de la muestra con la curva de calibración está en el año 795. La curva de calibración utilizada en las tres muestras es la publicada por M. Stuiver et al., 1998, en la revista Radiocarbon, 40 (3), p. xii-xiii. rezcan aún las características ollas con carena en el hombro).

\section{ELEMENTOS DE DISCUSIÓN}

\subsection{Definición e interpretación: los Balcanes, In- glaterra y Francia}

En este apartado se hará un sucinto repaso a los principales temas de debate presentes en la bibliografía reciente sobre este género de estructuras en diferentes partes de Europa. Una de las discusiones recurrentes acerca de la naturaleza de estas cabañas sigue siendo su interpretación o no como estructuras residenciales. En ámbito eslavo, estas construcciones se interpretan con una función residencial primordial ${ }^{21}$ (Milosevic, 1998: 243). La rica evidencia etnográfica sobre casas rurales de los siglos XIX $\mathrm{y}$ principios del $\mathrm{xx}$ sugiere una pervivencia de rasgos comunes desde la Edad Media (Id.: 250). La vivienda más representativa de las tribus eslavas era la construida con una única habitación semiexcavada (burdelj) o construida sobre el suelo con paredes de madera, piedra o tierra (dependiendo del material disponible). Los criterios seguidos para la sistematización tipológica de estas estructuras en la antigua Serbia parten de la organización del espacio interior y del sistema constructivo utilizado. Las viviendas de habitación única (el modelo más sencillo), tienen una superficie interior de entre 5,5 y $20 \mathrm{~m}^{2}$, corres-

21 Aunque también es cierto que en los asentamientos eslavos se reconocen algunas cabañas mayores "singulares» (asimilables a nuestro grupo B3) entre las Grubenhäuser de menor tamaño y más numerosas (Rusanova-Timoshuk, 1984: 66-67). 

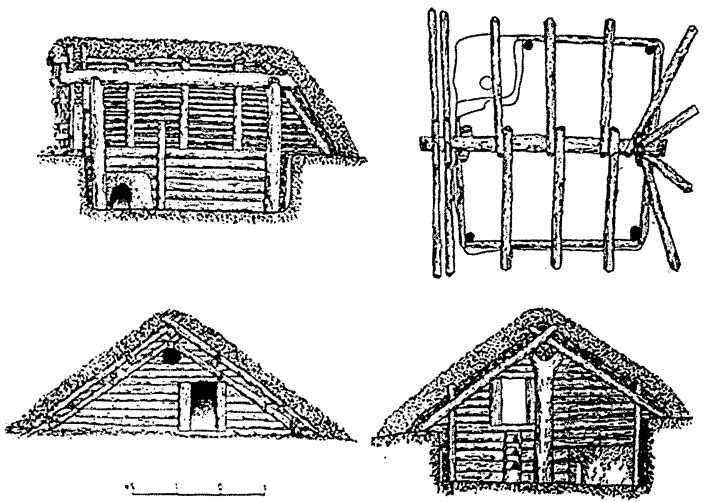

Fig. 28.-Cabañas rusas del siglo XI (estructura y recons-trucción). Tomado de Milosevic, 1998: fig. 179.

।

pondiente a las necesidades de una familia. Un elemento básico de su espacio interior es el hogar u horno. Su número o disposición permite una ulterior división (Milosevic, 1998: 245):

- Cabañas sin hogar ni horno. Son de pequeño tamaño y están representadas en escaso número de excavaciones. Un registro arqueológico deficiente por lo referido a los fuegos a duras penas facilitará inferencias sobre la utilización de la estructura como residencia o si su propósito se pudiera relacionar con actividades económicas o fines auxiliares, aunque están documentadas en la arquitectura tradicional (vajat) como refugio nocturno o residencia temporal de sus moradores.

- Cabañas con un solo hogar u horno en su interior, normalmente localizado en una de sus esquinas. La solera del horno o el hogar se dispone al nivel de suelo de la estructura o parcialmente excavado en él. Sólo de manera excepcional aparecen dispuestos a ras del suelo en el exterior del hoyo ${ }^{22}$.

Una variante de cabaña registrada arqueológica y etnográficamente en los Balcanes presenta una división interior en dos o más estancias, de manera que se aislaba el dormitorio del espacio para trabajar o vivir. Aunque aparecen desde contextos del siglo VIII, son más frecuentes a partir del XII.

${ }^{22}$ Normalmente el fuego no se apagaba, y la temperatura en el interior de la cabaña (especialmente en los meses estivales) era bastante alta. Por este motivo, en algunos casos, los hornos se situaban inmediatamente al exterior de la estructura mientras que su uso tenía lugar desde el interior, siendo esta solución racional una característica de algunas cabañas semiexcavadas. El nivel de la solera de los hornos (de planta circular u oval con semibóveda y tiro de salida de humo) era normalmente algo más alto que el del suelo de la cabaña, facilitando su manejo (Milosevic, 1998: 245). Algunas cabañas disponían de hornos u hogares de uso estival (el exterior) e invernal (el hogar interior).

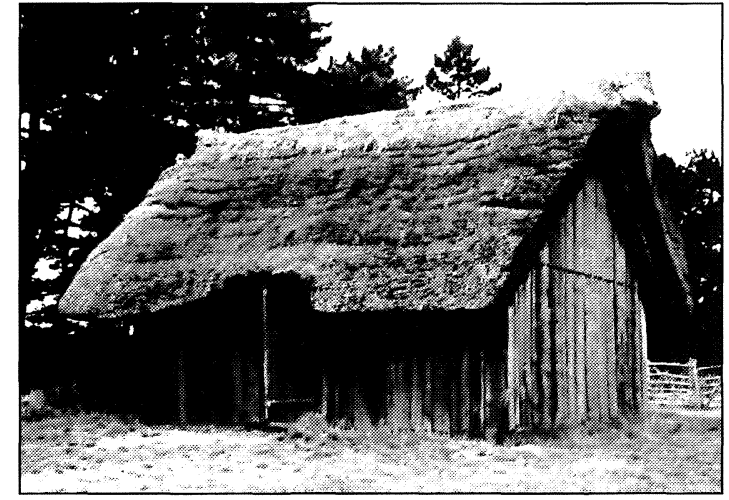

Fig. 29.-Reconstrucción de una de las cabañas de West Stow (Suffolk).

Por lo que se refiere a los sistemas constructivos, las paredes de las cabañas semiexcavadas eran construidas a partir de vigas o tableros horizontales o con apoyos estructurales de pies derechos (fig. 28).

En Inglaterra, E.T. Leeds comenzó a excavar fondos de cabaña sajones en Sutton Courtenay, durante los años veinte. Durante más de 50 años, estos «hoyos con techo» fueron el exponente más habitual de las excavaciones de sitios anglosajones. Desde su descubrimiento inicial, la interpretación de las «Grubenhäuser» (o «sunken featured buildings») como refugio o vivienda de pueblos en movimiento se mantuvo hasta la década de los sesenta, cuando comenzaron a identificarse otras estructuras más lógicamente atribuibles a un fin residencial (las «long houses» de planta rectangular, construidas en madera con vigas horizontales o postes verticales). Las excavaciones extensivas de West Stow (en Suffolk) permitieron las primeras reconstrucciones fiables de las cabañas semiexcavadas (fig. 29). Allí se sugirió que algunas de éstas incorporaron suelos de planchas de madera (West, 1985). En West Heslerton (North Yorkshire) tampoco se han hallado pruebas de la utilización del fondo de las cabañas como suelo (Powlesland, 1998: 3-6-2). La acusada diferencia de tamaño entre las grandes cabañas y las pequeñas, según Rahtz, podría significar que unas corresponden a la totalidad del espacio residencial mientras que las otras serían sólo la parte rehundida de estructuras mayores, ya que, a veces, aparecen huellas de postes fuera del hoyo (Rahtz, 1986: 75-76).

A partir de la obra clásica de Wilson (1986) se reconoce el problema de discriminar entre el periodo de uso de la estructura y el momento de su abandono, cuando el hoyo pasa a colmatarse de forma natural o sirve de basurero para los desechos domésticos (Rahtz, 1986: 73). El reconocimiento de 

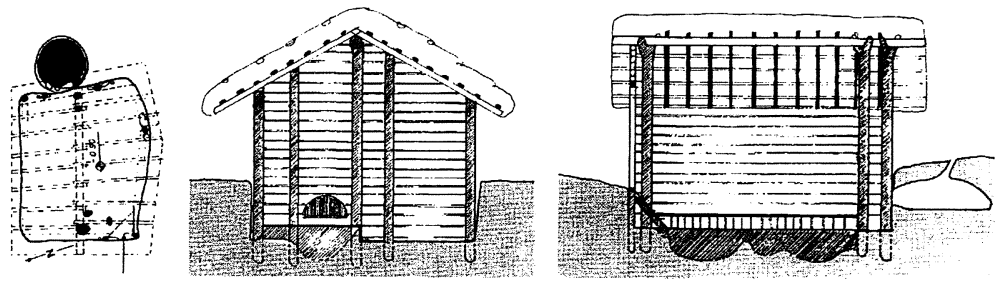

Fig. 30.-Reconstrucción de una cabaña con horno de Ribnica (Serbia). Tomado de Milosevic, 1998: fig. 162

este hecho aún sigue causando interferencias o colisiones interpretativas de cierta gravedad. En West Heslerton se identifican usos secundarios del interior de las mismas como ahumadero (por la presencia de una zona amplia de hogar) y cocina (por la presencia de un horno de cocción de alimentos). Su apuesta por una interpretación de las mismas como estructuras de usos múltiples («general purpose buildings») sigue sin ser totalmente convincente, mientras que la identificación de un cierto número de cabañas como almacenes de grano puede ser aún una confusión entre el uso original de la misma y los materiales presentes en los estratos que luego rellenaron el hoyo. Del mismo modo, se rechaza la antigua suposición de que se trataba de cabañas para el tejido o hilado a pesar de la cantidad de pesas de telar que suelen recuperarse en los depósitos de amortización (otra posibilidad más radicaría en la identificación segura de algunas huellas de poste verticales de pequeño tamaño como el apoyo de bastidores de telares verticales, aunque serían fácilmente confundibles con las huellas de bancos o de otros elementos interiores). La propuesta de interpretación de estas cabañas como estructura residencial de los estratos más bajos de la población queda también desechada sin demasiados argumentos por los responsables de West Heslerton debido a las condiciones ambientales «insanas» imperantes en la zona artesanal del yacimiento, en la que son mayoritarias estas construcciones, dada la presencia de «grandes cantidades de huesos de animales, incluyendo carcasas enteras», recuperadas tanto en el interior de los hoyos como en los estratos superficiales adyacentes (Powlesland, 1998: 3-6-2 y 6-5-5). Algunos autores han planteado la posibilidad de que estas estructuras fueran simples bodegas, o que el hoyo se rellenaba de paja para que su fermentación invernal produjera calor. Otros, en fin, consideran la posibilidad de que en algunos casos se tratara de espacios para la elaboración de derivados lácteos (Chapelot-Fossier, 1980: 121-131).

En Francia estas cabañas eran estructuras casi desconocidas antes de los años ochenta (con algu- nas notables excepciones). La multiplicación de excavaciones arqueológicas de urgencia en extensión ha facilitado su reconocimiento, por el momento, en casi toda la mitad norte del país. Han intentado establecerse clasificaciones dependiendo del número y disposición de los postes (con dos axiales, con cuatro en las esquinas, con seis, sin postes, etc.). Las huellas de diversos aparejos internos permiten identificar la supuesta función de las cabañas como talleres textiles, metalúrgicos, alfareros, secaderos o cocederos (por la presencia de hornos $\mathrm{u}$ hogares), aunque la existencia de estructuras de fuego en su interior (y en algunos casos una mayor superficie útil interior) avalaría su interpretación como estructura residencial (Peytremann, 1995: 8).

\subsection{La posible etnicidad derivada de uno de los modelos de cabaña (o su especificidad crono- lógica)}

La discusión sobre una posible correspondencia entre determinados tipos de cabañas y uno u otro pueblo o entidad étnica tiene una bibliografía extensa cuyo punto de partida concierne al antiguo problema de la identificación de vestigios arqueológicos relacionados con las invasiones del siglo v. Durante mucho tiempo se creyó que los inquilinos de prácticamente todas las necrópolis datables en ese siglo eran germanos debido a diversos elementos de su indumentaria, como broches de cinturón, fíbulas u otros elementos. Reemplazadas esas ideas que convertirían a la península Ibérica en un feudo visigodo sin apenas población indígena y aceptada la tesis que sostiene una germanización en la moda o en algunas formas de vestir, se ha llegado en la actualidad a sostener en la práctica la idea contraria: los visigodos, debido a su escaso número, se asentaron en las ciudades en las que debían mantenerse guarniciones siendo improbable encontrar otros restos arqueológicos de una migración popular (germanos en aldeas campesinas).

Sin ánimo de entrar a fondo en esta espinosa cuestión, desde otros ámbitos europeos se ha debatido y se discute en la actualidad acerca de si algunos elementos del registro arqueológico (como las Grubenhäuser) pueden ser considerados o no un elemento de identificación étnica válido (Snyder, 1997: 3), sobre todo cuando su aparición en Gran Bretaña coincide con la llegada de elementos sajo- 
nes a la isla y teniendo en cuenta que la tradición indígena en esa misma época y en la inmediatamente anterior aporta otro tipo de ejemplos y soluciones constructivas bien diferentes. En Francia, algunos trabajos recientes apuntan la posibilidad de identificación de los poblados de cabañas de este tipo con las áreas de asentamiento de francos, alemanes y sajones al norte y este del Loira (Farnoux, 1995: 29-44). El problema, en parte, tiene raíces más profundas: por ejemplo, se desconoce si los mapas de distribución de los poblados de cabañas en Francia no obedecen más a desigualdades en la práctica arqueológica (desde el empleo de una metodología inapropiada al grado de cumplimiento de la legislación sobre Patrimonio Histórico seguido en la ejecución de las grandes obras públicas y de infraestructuras) que a una auténtica distribución regional diferencial de los mismos. Cuando se considera el intenso regionalismo de la época (y de los diversos territorios europeos) uno de los aspectos que más interrogantes plantea se refiere a la repetición de un mismo modelo a escala continental a lo largo de toda la Edad Oscura y todo lo referido a a la interpretación correcta del fenómeno (Dixon, 1982: 282).

\subsection{Viviendas y estructuras auxiliares. Hornos y hogares}

Hasta fechas recientes, los ejemplos de cabañas con hogares $u$ hornos interiores en Francia no sobrepasaban los ocho casos (Peytremann, 1995: 8) y tampoco parecen ser habituales en los yacimientos ingleses. Este dato contrasta con su aparición generalizada en las cabañas de la Europa eslava (Donat, 1980: 62-3; Milosevic, 1998: 245. Fig. 30).

La importancia de esta asociación reside sobre todo en que podría ser indicadora de un uso residencial de la construcción. La ausencia (o dificultad de reconocimiento arqueológico) de este tipo de elementos en el interior de las cabañas semiexcavadas del Occidente ha provocado un sinfín de interpretaciones funcionales diferentes hasta llegar a la ecléctica solución de los «edificios de usos múltiples». En el caso que nos ocupa, los poblados madrileños certifican no sólo la presencia de cabañas con hornos en un número no despreciable de casos, sino la existencia de estructuras interiores, pavimentos, sistemas de acceso, etc., que serían garantía de un uso residencial de las mismas, aunque también es cierta la dificultad de reconocimiento de estos elementos en muchos otros casos. La documentación de estratos de preparación del suelo en algunas de las caba-

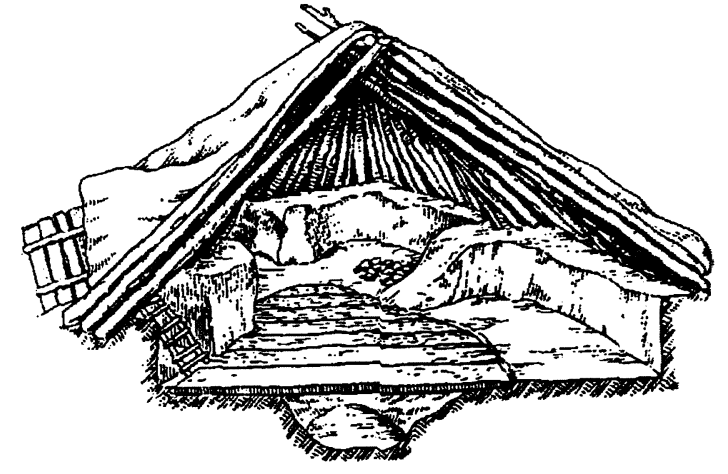

Fig. 31.-Reconstrucción de una cabaña con solera de madera de Suzdalj (Rusia). Tomado de Milosevic, 1998: fig. 175.

ñas excavadas no implica, sin embargo, que se descarte en otras ocasiones la posible existencia de soleras de madera cubriendo la parte excavada del hoyo, que podría usarse como bodega bajo el suelo de la cabaña (fig. 31). Por último, la documentación de sistemas de acceso al interior del hoyo desde el exterior (por rampas, escalones excavados u otros sistemas) demuestran un uso de esa parte subterránea de las cabañas incompatible con algunas de las interpretaciones tradicionales vistas anteriormente. En un caso excepcional (debido a la conservación casi íntegra de la cota de frecuentación exterior) se intuye la posibilidad de que un conjunto formado por una cabaña semiexcavada y un hoyo de almacenamiento hayan compartido una misma cubierta ${ }^{23}$.

\subsection{Las casas con cimientos de piedra como evo- lución (o desarrollo) del tipo B3}

La posible sustitución de algunas antiguas cabañas por casas con cimientos en piedra podría manifestarse a través del reemplazo generalizado de las primeras por las segundas en algún momento avanzado del siglo VII ${ }^{24}$. De hecho, algunas de las casas construidas con cimientos de piedra en las laderas del yacimiento de Gózquez presentan un perfil semirrupestre, con excavación de la parte alta y regularización horizontal del suelo mediante el tallado de la roca. Las dimensiones de las habitaciones con

${ }^{23}$ Una huella de poste exterior quedaba alineada con las registradas en el suelo de la cabaña y se conservaban estratos horizontales de frecuentación en la probable ubicación del acceso al conjunto.

${ }^{24}$ Este fenómeno ha sido observado también en el poblado altomedieval de l'Aiguacuit, en Tarrasa (Coll i Riera y Molina, 1993: 74). 
hogar de estas verdaderas casas con cimientos de mampostería, alzados en tapial de yeso y cubierta de teja curva resultan sólo algo mayores que las de algunas de las cabañas del tipo B3 (compárense los $13,6 \mathrm{~m}^{2}$ de la habitación sudeste del edificio $15 \mathrm{de}$ Gózquez con los $16,7 \mathrm{~m}^{2}$ de la cabaña L.2150, los $13,8 \mathrm{~m}^{2}$ de la cabaña G.6090 o los 13,3 de la G.6590).

El análisis diacrónico de la parte excavada del yacimiento de Gózquez indica la existencia y perduración en el tiempo de un sistema de agrupamiento de estructuras menores en torno a una cabaña grande. Este sistema sólo varía durante las dos últimas fases del poblado, cuando las estructuras auxiliares parecen pasar a agruparse en torno a las casas, que muestran paralelos muy estrechos con las documentadas en poblados de cronología tardovisigoda, como los de Navalvillar, Boadilla del Monte, Tolmo de Minateda o El Cañal ${ }^{25}$.

\subsection{Posibles pautas sociales derivadas del regis- tro arqueológico}

La parte excavada de los poblados de Pinto y San Martín de la Vega ofrece una imagen inequívoca de asentamientos rurales abiertos con un modelo de organización espacial dispersa hacia el interior, aunque previsiblemente con unos límites fijados desde el inicio (posiblemente a partir del establecimiento de las lindes de las parcelas cultivadas). El espacio ocupado por estructuras arqueológicas de cierto relieve formando agrupaciones (de posible carácter familiar) alterna con amplios sectores vacíos, posiblemente destinados a determinadas actividades cuyo rastro no ha pervivido ${ }^{26}$. Durante el transcurso de la ocupación, el poblado no parece aumentar de tamaño, ni se explicita una ganancia de nuevos espacios significativos, sino que las nuevas construcciones se insertan en la disposición original

${ }_{25}$ Navalvillar, Madrid (Caballero, 1989: fig. 8); Boadilla, Madrid (Alfaro y Martín, 2000: fig. 3); Tolmo de Minateda, Albacete (Gutiérrez, 1999: fig. 13 y lám. IV); El Cañal, Salamanca (Storch, 1997: fig. 2).

${ }^{26}$ Este mismo patrón se ha observado en el yacimiento de West Heslerton (North Yorkshire, Inglaterra), que es el asentamiento más extensamente excavado de su clase en las islas Británicas (Powlesland, 1998: 6.5.2). La fase anglosajona antigua (desde finales del siglo $\mathrm{v}$ a mediados del vil d.n.e.) cubre una superficie de más de 13 hectáreas, en las que se han excavado 220 estructuras de todo tipo, incluyendo 130 Grubenhäuser y 90 estructuras sobre postes. Los otros dos yacimientos británicos excavados ampliamente son West Stow (Suffolk) y Mucking (Essex). El modelo de asentamiento propuesto para West Stow sugiere una pauta no preestablecida, de modo que diversas granjas familiares dispersas en racimos irían mudando su ubicación con el tiempo. procurando rellenar huecos a la vez que se evita escrupulosamente interferir con estructuras amortizadas anteriormente (quizás por precaución ante una posible contaminación). El poblado de Gózquez parece mostrar un esquema global de uso del espacio en el que parcelas intensamente ocupadas por estructuras arqueológicas residenciales y de almacenamiento dejan intercaladas parcelas rectangulares sin evidencias arqueológicas que podrían interpretarse como espacios de trabajo agrícola (campos de labor) o recintos para animales ${ }^{27}$.

La población, de este modo, parece agruparse en núcleos independientes en torno a determinadas estructuras singulares (grandes cabañas del tipo A2 o B3), lo que podría interpretarse como un modelo «familiar» (en sentido extenso, o incluso «clánico») de ocupación ${ }^{28}$. Un rasgo significativo a tomar en consideración es la repetición de este modelo en las fases avanzadas del asentamiento, cuando las casas con cimientos de piedra parecen sustituir a las cabañas grandes como elemento aglutinador o de cohesión.

La presencia en la zona alta de la ladera de un único edificio de planta compleja (posiblemente ordenado en torno a un patio o corral) y su asociación y contemporaneidad en el uso con una construcción de uso no residencial (lagar o prensa) podría indicar la existencia de una administración independiente y jerárquicamente superior a las familias o una familia de mayor rango social (de no tratarse de estructuras de uso comunal). De momento, sin embargo, estas hipotéticas huellas de una eventual diferenciación social no parecen tener un referente explícito en el registro de la necrópolis (aún en fase de estudio). Además, los materiales de desecho doméstico (sobre todo cerámica y vidrio, aunque también los restos de fauna consumidos) no reflejan desigualdades apreciables entre los conjuntos.

Los sistemas de almacenamiento de cereal a largo plazo (silos) se concentran en determinadas zonas o se agrupan en hileras que permiten una vigilancia o sistema de control colectivo o familiar y una probable utilización coetánea de varias de estas estructuras en batería. Su presencia indica sin lugar a dudas la estabilidad de la población y su fijación al

27 Otras zonas vacías de forma circular y menor extensión rodeadas por estructuras arqueológicas heterogéneas podrían corresponder a áreas de uso comunal, o a corrales.

28 Para un modelo de unidad de explotación familiar véase el caso de la aldea sajona de Warendorf (Westfalia), compuesto por una casa grande, dos cobertizos protectores de los molinos de cereal, 3 o 4 cabañas excavadas y $8 / 10$ construcciones aéreas, residenciales o auxiliares, dispuestas sobre una extensión aproximada de $50 \times 70$ metros (Chapelot-Fossier, 1980: 79-88) 
territorio, descartando cualquier posible interpretación estacional del uso del yacimiento y restringiendo su posible movilidad ${ }^{29}$.

\section{CONCLUSIONES}

Por vez primera se reúne un catálogo de estructuras asignables de manera inequívoca a un tipo de arquitectura profana de carácter netamente rural cuyas dificultades de reconocimiento arqueológico las ha hecho invisibles a la literatura arqueológica española del periodo al que nos referimos. Sus paralelos con las cabañas del resto de Europa en momentos similares y las posibilidades de interpretación que proporciona la inferencia etnográfica con otras regiones del continente han servido para ilustrar someramente el funcionamiento y las opciones de reconstrucción de la parte «aérea» de estas cabañas, sin la cual nos encontraremos siempre exclusivamente con un hoyo en el terreno de una forma y unas determinadas características, no siempre sencillas de reconocer. Una parte de las mismas (el tipo más simple de cabaña excavada de planta ovalada) parece responder a una tradición vernácula que se remontaría al menos al Bronce Pleno, aunque faltaría por documentar su presencia en época romana. Otros tipos (los de planta rectangular) podrían relacionarse con tradiciones constructivas trasladadas a nuevos territorios por pueblos inmigrantes o simplemente responder a determinadas necesidades o soluciones correspondientes a una época precisa. Esperamos que las premisas metodológicas esbozadas para la correcta documentación de este tipo de evidencias y el grupo de ejemplos expuestos sirvan de ayuda y acicate a la identificación de nuevos poblados formados por cabañas en otras partes de nuestra geografía y a un mayor esfuerzo hacia una adecuada interpretación de muchas estructuras arqueológicas hasta hace poco tiempo desdeñadas.

\section{BIBLIOGRAFÍA}

Alfaro Arregui, M. y Martín Bañón, A. (2000): «La Vega, asentamiento visigodo en Boadilla del Monte (Madrid)», en Ruano, E. (dir.) La Arqueología madrileña en el final del siglo $\mathrm{xx}$ : desde la

${ }^{29}$ En este sentido, descartamos tajantemente la vinculación propuesta de los poblados de cabañas con una dedicación ganadera de sus habitantes, como se ha publicado recientemente (Fuentes, 2000: 206-7). La explotación ganadera de áreas marginales (la propuesta publicada) constituiría en último término sólo un complemento a una práctica agrícola dominante. prehistoria hasta el año 2000, Boletín de la Asociación Española de Amigos de la Arqueología, 39-40, pp. 225-238.

Aquilué Abadías, X. (1993): «Las cerámicas finas de los niveles tardorromanos» en Dupré, X. y Carreté, J.M., La «Antiga Audiència», Excavaciones Arqueológicas en España, 165, pp. 117-150.

Caballero Zoreda, L. (1989): «Cerámicas de 'época visigoda y postvisigoda' de las provincias de Cáceres, Madrid y Segovia», Boletín de Arqueología Medieval, 3, pp. 75-108.

Coll I Riera, J.M. y Molina, J.-A. (1993): «L'Aiguacuit (Terrassa, Vallès Occidental). La transformació d'una vila romana en un vilatge medieval», IV Congreso de Arqueología Medieval Española (resúmenes), Alicante, p. 74.

Chapelot, J., Fossier, R. (1980): Le village et la maison au Moyen Âge. Paris.

Dixon, Ph. (1982): «How Saxon is the Saxon House», en Drury, P.J. (ed.), Structural Reconstruction (Approaches to the interpretation of the excavated remains of buildings). B.A.R., British Series, 110, Oxford, pp. 275-289.

Donat, P. (1980): «Haus, Hof und Dorf in Mitteleuropa vom 7.-12. Jahrhundert», Schriften zur Urund Frühgeschichte, 33. Berlin.

FARNoux, Cl. (1995): «Le fond de cabane merovingienne comme fait culturel», en Lorren, $\mathrm{Cl}$. y Perin, P. (eds.), L'habitat rural du Haut Moyen Âge, Rouen, pp. 29-44.

Fuentes, A. (2000): «Una zona marginal de Hispania: Madrid en época romana», en Ruano, E. (dir.) La Arqueología madrileña en el final del siglo Xx: desde la prehistoria hasta el año 2000, Boletín de la Asociación Española de Amigos de la Arqueología, 39-40, pp. 197-211.

Gutiérrez Lloret, S. (1996): La Cora de Tudmir: de la antigüedad tardía al mundo islámico, (CCV, 57), Madrid-Alicante.

GutiérRez Lloret, S. (1999): «La cerámica emiral de Madinat Iyih (el Tolmo de Minateda, Hellín, Albacete). Una primera aproximación», Arqueología y Territorio Medieval, 6, pp. 71-112.

Hamerow, H. (1993): Excavations at Mucking. The anglo-saxon settlement. London.

Laiz Reverte, M.D. y Ruiz Valderas, E. (1988): «Cerámicas de cocina de los siglos V-VII en Cartagena (C/. Orcel-D. Gil)», Antigüedad y Cristianismo, V, pp. 265-301.

Martínez Navarrete, M.I. (1979): «El yacimiento de La Esgaravita (Alcalá de Henares, Madrid) y la cuestión de los llamados 'Fondos de cabaña' del valle del Manzanares», Trabajos de Prehistoria, 36, pp. 83-118. 
Milosevic, G. (1998): Housing in medieval Serbia. Belgrado (original en serbio con resumen en inglés).

Peytremann, E. (1995): «Les structures d'habitat rural du haut Moyen Âge en France ( $v^{\mathrm{e}}-\mathrm{X}^{\mathrm{e}} \mathrm{s}$.)», en Lorren, Cl. y Perin, P. (eds.), L'habitat rural du Haut Moyen Âge, Rouen, pp. 1-28.

Powlesland, D. (1998): «The West Heslerton Assessment», Internet Archaeology, 5 (http:// intarch.ac.uk/journal/issue5/westhes/).

RADFORD, C.A.R. (1957): «The Saxon House: a review and some parallels», Medieval Archaeology, 1, pp. 27-38.

RAHTZ, Ph. (1986): «Buildings and rural settlement» en D.M. Wilson, The archaeology of AngloSaxon England, pp. 49-98.

Ramon, J. y CAU, M.A. (1997): «Niveles de época vándala de Es Castell (Eivissa)», Arqueo Mediterrània, 2, pp. 269-311.

Rusanova, I.P. y Timoshuk, B.A. (1984): Kodyn-slavyanskie poçeleniya $V$-VIII vv. na r. Prut. Moscú (en ruso).

SNYDER, C.A. (1997): «A gazetteer of sub-Roman Britain (AD 400-600): the British Sites», Inter- net Archaeology, 3 (http://intarch.ac.uk/journal/ issue $3 /$ snyder/).

Storch DE Gracia, J.J. (1997): «Avance de las primeras actividades arqueológicas en los hispanovisigodos de La Dehesa del Cañal (Pelayos, Salamanca)», Arqueología, Paleontología y Etnografía, 4, pp. 141-160.

Vicent García, J.M. (1998): «La prehistoria del modo tributario de producción», Hispania, LVIII/3, num. 200, pp. 823-839.

VigiL-EscalerA, A. (1997): «La Indiana (Pinto, Madrid): estructuras de habitación y de uso hidráulico de una comunidad campesina (siglos VI-X d.n.e.)», XXIV Congreso Nacional de Arqueología (Cartagena, octubre 1997), Cartagena, p. 314.

Vigil-Escalera, A. (e.p.): «Evolución de los morfotipos de cerámica común de un asentamiento rural visigodo de la Meseta (Gózquez deArriba, S. Martín de laVega, Madrid)», Arqueohispania, 0 (http:/ /teleline.terra.es/personal/jtovar/journal. htm).

WeST, S.E. (1985): The anglo-saxon village at West Stow, East Anglian Archaeology, 24.

WILson, D., ed. (1986, ed. orig. 1976): The archaeology of Anglo Saxon England. New York. 